\title{
Calebin A: Analytical Development for Pharmacokinetics Study, Elucidation of Pharmacological Activities and Content Analysis of Natural Health Products
}

\author{
Ana Luísa de P. Oliveira ${ }^{1}$, Stephanie E. Martinez ${ }^{1}$, Kalyanam Nagabushnam ${ }^{2}$, Muhammed Majeed ${ }^{2}$, Samaa Alrushaid ${ }^{1}$, \\ Casey L. Sayre ${ }^{1}$ and Neal M. Davies ${ }^{1}$ \\ ${ }^{1}$ College of Pharmacy, Faculty of Health Sciences, University of Manitoba, Winnipeg, Manitoba, Canada ${ }^{2 . .}$ Sabinsa \\ Corporation, 20 Lake Drive, East Windsor NJ.
}

Received, July 6, 2015; Revised, September 10, 2015; Accepted, September 24, 2015; Published, September 30, 2015.

\begin{abstract}
Purpose: To develop a bioanalytical assay using RP-HPLC to quantify the curcuminoid calebin A, to characterize its pharmacokinetics in rats after intravenous (IV) and oral (PO) administration, to identify its pharmacological activities and to evaluate its content in natural health products. Methods: An RP-HPLC method was developed for the detection of calebin A. Separation was carried out using a Phenomenex ${ }^{\circledR}$ Kinetex ${ }^{\circledR}$ C18 column with UV detection at $339 \mathrm{~nm}$. An isocratic mobile phase consisting of acetonitrile and water with $10 \mathrm{mM}$ ammonium formate $(\mathrm{pH} 7.0)(40: 60, \mathrm{v} / \mathrm{v})$ at a flow rate of $0.8 \mathrm{~mL} / \mathrm{min}$ was employed. Linear standard curves were established and applied in the pharmacokinetic study. Calebin A was administered to male Sprague-Dawley (CD) rats IV $(20 \mathrm{mg} / \mathrm{kg})$ or PO $(500 \mathrm{mg} / \mathrm{kg})(n=4 /$ route of administration). Serum and urine samples were collected for $72 \mathrm{~h}$ post dose. In vitro antioxidant activity, anti-inflammatory activity (cyclooxygenase and lipoxygenase inhibition), dipeptidyl peptidase-4 (DPP-4) inhibition and cytochrome P450 inhibitory activties of calebin A were examined using commercial assay kits. Content analysis of calebin A in 14 natural health products advertised to contain turmeric were carried out using methanolic extraction. Results: The HPLC method was successfully applied to a pharmacokinetic study of calebin A in rats. After IV and PO administration of calebin A, the compound was detected as the aglycone and a glucuronidated metabolite. Oral bioavailabitily was found to be $\sim 0.5 \%$, serum half-life was $\sim 1-3 \mathrm{~h}$. Calebin A appears to be primarily excreted via non-renal routes. Calebin A possessed concentration-dependent antioxidant activity and DPP-4 inhibition. Calebin A appears to be a non-selective cyclooxygenase inhibitor and also a poor lipoxygenase inhibitor. The curcuminoid displayed in vitro interactions with CYP2D6 and CYP1A2. Content analysis of 14 natural health products that claimed to contain turmeric showed that concentration of calebin A was inconsistent among the products. Conclusion: A successful assay was developed for the detection of calebin A using RP-HPLC. Preliminary pharmacokinetic studies indicate that an unoptimised formulation of calebin A has poor oral bioavailability. Calebin A exhibits various pharmacological activities.
\end{abstract}

This article is open to POST-PUBLICATION REVIEW. Registered readers (see "For Readers") may comment by clicking on ABSTRACT on the issue's contents page.

\section{INTRODUCTION}

Calebin A ((3E)-4-(4-Hydroxy-3-methoxyphenyl)2-oxo-3-buten-1-yl (2E)-3-(4-hydroxy-3methoxyphenyl) acrylate) (Figure 1) is a curcuminoid derived from turmeric (Curcuma longa, Zingeberaceae) (1). Turmeric is a traditional natural product in Asian medicine and it has been used as a spice, pigment and herbal product with pharmaceutical properties $(2,3)$.

Studies show that it has anti-inflamatory, antioxidant, anti-cancer and anti-diabetic activities as well as several other biological responses (4).
One of the best studied curcuminoid active ingredients of turmeric is curcumin. However, it has been demonstrated that there are other compounds in turmeric that may have potential pharmacological activities $(4,5)$.

Corresponding Author: Dr. Neal M. Davies, College of Pharmacy, Faculty of Health Sciences, University of Manitoba, 750 McDermot Avenue, R3E OT5, Winnipeg, Manitoba, Canada. Email: Neal.Davies@umanitoba.ca 
Calebin $\mathrm{A}$ is one of these compounds, and it has been shown to protect cells from $\beta$-amyloid insult and to exhibit anti-tumor activity in gastric cells $(1,2,4)$.

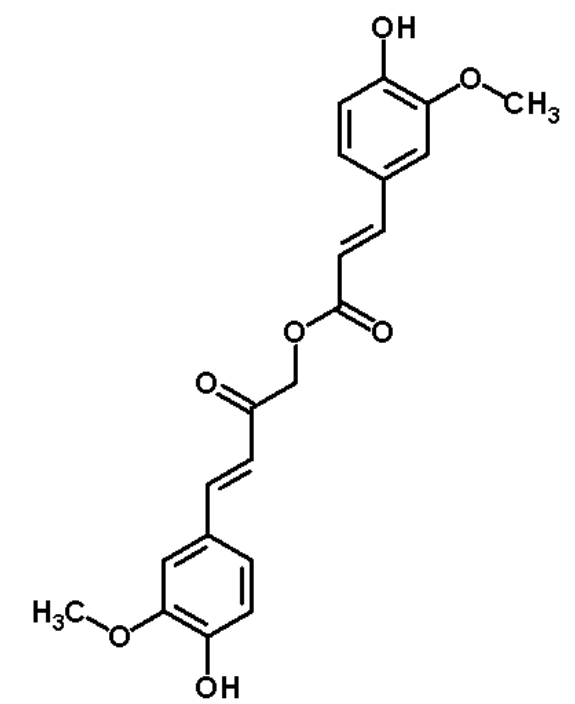

Figure 1. Chemical structure of calebin A

Currently, there are few studies in the literature that examine calebin A's pharmacokinetics and pharmacodynamics. It is necessary to describe pharmacokinetic disposition, safety, and the potential health benefits of the compound as it is widely available in some natural health products. The purpose of this study was to develop a bioanalytical method for detection of calebin A using reverse-phase high-performance liquid chromatography (RP-HPLC), to characterize the pharmacokinetics of calebin $\mathrm{A}$ in rats after intravenous (IV) and oral (PO) administration, to identify its pharmacological activities and to assess the content of calebin A in commercially available natural health products.

A reliable, sensitive and accurate analytical method is essential to delineate the pharmacokinetic disposition in a rat model. In the present study serum and urine concentration time curves were established and analyzed to obtain valuable pharmacokinetic parameters for calebin A such as the half-life $\left(t_{1 / 2}\right)$ of the compound, volume of distribution $\left(\mathrm{V}_{\mathrm{d}}\right)$, clearance $(\mathrm{CL})$ and bioavailability (F). Moreover, the urine samples were also analyzed for changes in electrolytes and renal injury markers to determine if calebin A possesses renal toxicity. The pharmacological activities of calebin A were also elucidated. The anti-oxidant capacity, anti-inflammatory activities and anti-diabetic activities of calebin A were performed using in vitro assays. The inhibition of common drugmetabolizing enzymes found in the body by calebin A was also assessed using in vitro assays. The quantity of individual chemical constituents of commercially available natural health products are sometimes not reported on the label. Furthermore, quality control and good manufacturing practices of certain natural health products can be questionable. Therefore, several commercially available natural health products containing turmeric were analyzed for calebin A content using the developed method of analysis to determine uniformity of the manufacturing progress.

\section{MATERIALS AND METHODS}

\section{Chemicals and Reagents}

Calebin A was provided by Sabinsa Corpotation ${ }^{\circledR}$ (Piscataway, NJ, USA). Apigenin was obtained from Sigma-Aldrich (St. Louis, MO, USA). HPLCgrade acetonitrile was purchased from Fisher Scientific (Pittsburgh, PA, USA). The antioxidant activity kit, cyclooxygenase-1 and -2 inhibitor screening kits, lipoxygenase inhibitor screening kit and dipeptidyl peptidase-4 (DDP-4) inhibitor screening assay kit were purchased from Cayman Chemical Company (Ann Arbor, MI, USA). Vivid ${ }^{\circledR}$ CYP2C9 green screening kit, Vivid ${ }^{\circledR}$ CYP3A4 green screening kit, Vivid ${ }$ CYP1A2 blue screening kit and Vivid ${ }^{\circledR}$ CYP2D6 blue screening kit were bought from Life Technologies (Burlington, ON, Canada). CanPrev Digestion \& IBS, OM3 Memory and MacroLife Natural Miracle Reds Cardio Anti-oxidant Superfood were bought from Well.ca (Guelph, ON, CA). ProCreation Female Fertility Support, Himalaia Herbal Healthcare DermaCare, HerbalFactors Liv-Gall Cleanse, Planetary Herbals Myelin Sheath Support, Turmeric Ginger Joint Ease, Nature's Bounty Turmeric, Himalaia Herbal Healthcare HemoCare, Thompson Turmeric Curcumin, Zand Decongest Herbal, Planetary Herbals Stone Free were purchased from iHerB.com (Morino Valley, CA, USA).

\section{Analytical Development Preparation of Standard Solutions}

Stock solutions of calebin A $(100 \mu \mathrm{g} / \mathrm{mL})$ and the internal standard (IS) apigenin $(100 \mu \mathrm{g} / \mathrm{mL})$ were prepared in methanol. Using the stock solutions of calebin A, calibration standards in urine and serum 
were prepared by sequential dilution with blank rat urine and serum. A series of concentrations were obtained, particularly $0.05,0.1,0.5,1.0,5.0,10.0$, and $50 \mu \mathrm{g} / \mathrm{mL}$. Moreover, quality control samples were prepared from stock solution of calebin A by dilution with blank rat urine and serum to obtain low, medium and high concentrations $(0.075,0.75$, 7.5 and $25.0 \mu \mathrm{g} / \mathrm{mL}$ ). All stock solutions were stored at $-20^{\circ} \mathrm{C}$ and protected from light.

\section{Sample Preparation}

The standard solution of calebin A $(25,50$ or 100 $\mu \mathrm{L})$, IS $(50 \mu \mathrm{L})$ and blank rat urine or serum $(100$ $\mu \mathrm{L}$ ) were put in $2.0 \mathrm{~mL}$ Eppendorf tubes. $1 \mathrm{~mL}$ of cold acetonitrile was added to precipitate the proteins in serum or urine standard curve samples. The standards were vortex mixed (Vortex Genie-2, VWR Scientific, West Chester, PA, USA) and centrifuged at 15,000 rpm for 5 min (Beckman Microfuge centrifuge, Beckman Coulter Inc., Fullerton, CA, USA). The supernatant was collected, transferred to clean Eppendorf tubes, and dried under nitrogen gas until completely dry. The residue was reconstituted with $200 \mu \mathrm{L}$ of the mobile phase, vortex mixed for $30 \mathrm{~s}$ and centrifuged at $15,000 \mathrm{rpm}$ for $5 \mathrm{~min}$. The supernatant was transferred to HPLC vials and $50 \mu \mathrm{L}$ of the solution was injected into the HPLC system.

\section{HPLC Analysis and Conditions}

The HPLC system used was a Shimadzu HPLC (Kyoto, Japan). The compounds were separated on a C18 Phenomenex Kintex ${ }^{\circledR}$ column $(2,6 \mu, 100 \mathrm{x}$ $4.60 \mathrm{~mm}$ ). A buffer solution was prepared by dissolving $1.5 \mathrm{~mL}$ of ammonium formate in $1 \mathrm{~L}$ of water and the $\mathrm{pH}$ was adjusted to 7.0. The mobile phase was prepared by mixing acetonitrile with the buffer solution $(40: 60, \mathrm{v} / \mathrm{v})$. The flow rate was kept at $0.8 \mathrm{~mL} / \mathrm{min}$ with ultraviolet detection wavelength set at $339 \mathrm{~nm}$. The separation was carried out at room temperature $\left(25 \pm 1^{\circ} \mathrm{C}\right)$. Shimadzu EZStart (Version 7.4) software was used for data collection and integration.

\section{Accuracy, Precision and Recovery}

Inter- and intra-day run samples were prepared in a series of concentrations $(0.05,0.1,0.5,1.0,5.0$, 10.0 and $50.0 \mu \mathrm{g} / \mathrm{mL}$ ). The intraday run precision and accuracy were evaluated from repetitive injections in seven different days. The interday run precision and accuracy was measured from six consecutive injections in one day. Relative standard deviation (RSD) was used to evaluate the precision and the accuracy was estimated from the mean percentage error of weighed concentration to the actual concentration. The recovery samples were prepared from stock solutions of calebin A at the same concentration described above, but without matrix (serum or urine). The samples were injected into the HPLC system in triplicates. The results were defined by comparing the peak area ratio (PAR) of calebin A and IS to the PAR of inter- and intraday run.

\section{Stability}

The freeze-thaw stability of calebin A in rat urine and serum was measured in ten concentrations $(0.05,0.075,0.1,0.5,0.75,1.0,5.0,7.5,10.0,25.0$ and $50.0 \mu \mathrm{g} / \mathrm{mL}$ ). The samples were prepared and evaluated and then they were kept at $-20^{\circ} \mathrm{C}$, thawed at room temperature $\left(25 \pm 1^{\circ} \mathrm{C}\right)$ and injected into the HPLC system. This cycle was repeated three times. The auto-injector stability was estimated using samples at the same concentrations described above. On the day of the analysis, samples were prepared and injected into the HPLC system. The samples were kept in the same rack overnight, and they were injected again after $24 \mathrm{~h}$.

\section{Data Analysis}

Calibration curves were obtained by plotting the peak area ratio of calebin A to the internal standard versus calibration standards concentration, through the unweighted least squares linear regression.

\section{Animals and Surgical Procedures}

Male Sprague-Dawley rats ( $300 \mathrm{~g})$ were obtained from Charles River Labs (Montreal, Canada). The rats were housed in a temperature and humiditycontrolled room at the animal care facility with $12: 12 \mathrm{~h}$ light-dark cycle without restriction from food and water. Firstly, the rats were anesthetized using isoflurane (IsoFlo, Abbott Laboratories, Abbot Park, IL, USA) coupled with an oxygen regulator to ensure the surgical plane of anesthesia. Afterwards, sterile silastic cannulas (Dow Corning, Midland, MI, USA) were cannulated in the right jugular vein of each rat and through the dorsal skin an intramedic PE-50 polyethylene tubing (Becton, Dickinson and Company, Franklin Lakes, NJ, USA) was inserted. A non-heparinized $0.9 \%$ sterile saline solution was used to flush the cannula. For recovery, the animals were single caged at the animal care facility with free access to food and 
water for at least 5 days before use. The animals were transferred to metabolic cages and maintained without food overnight, $12 \mathrm{~h}$ before dosing. University of Manitoba Office of Research Ethics and Compliance granted the animal ethics approval for our protocol; Approval Number - B2011064/1/2 (AC 10647)

\section{Pharmacokinetic Study}

On the day of the experiment, the animals were dosed IV (20 mg/kg, $\mathrm{n}=4)$ and PO (500 mg/kg, $\mathrm{n}=4)$ with calebin A in $98 \%$ of PEG 400 and $2 \%$ of DMSO. Afterwards, blood samples $(0.4 \mathrm{ml})$ were collected at 0,1 and $15 \mathrm{~min}$, and $0.5,1,2,4,6,12$, 24, 48 and $72 \mathrm{~h}$ for IV dosed rats. For PO dosed rats, blood samples were collected at $0,0.25,0.5,1$, 2, 4, 6, 12, 24 and $72 \mathrm{~h}$. Samples were collected in $2.0 \mathrm{~mL}$ Eppendorf tubes. After each sample collection, $0.5 \mathrm{ml} 0.9 \%$ non-heparinized saline solution was used to wash the cannula. Both blood and urine samples were centrifuged at 10,000 rpm for $5 \mathrm{~min}$. The serum was collected, divided into two $0.1 \mathrm{~mL}$ fractions and placed into $2.0 \mathrm{~mL}$ Eppendorf tubes. Samples were stored at $-20^{\circ} \mathrm{C}$ until their analysis. Urine samples were also collected at 2, $612,24,48$ and $72 \mathrm{~h}$ after calebin A administration. The volumes of urine produced were recorded and two $0.1 \mathrm{~mL}$ fractions, were placed into $2.0 \mathrm{~mL}$ Eppendorf tubes and stored at $20{ }^{\circ} \mathrm{C}$ until their analysis. $72 \mathrm{~h}$ after dose, the animals were euthanized, exsanguinated, and serum was collected.

\section{Serum and Urine Sample Preparation}

$50 \mu \mathrm{L}$ of serum and urine samples were run in duplicate with or without the addition of $10 \mu \mathrm{L}$ of $500 \mathrm{U} / \mathrm{mL} \beta$-glucuronidase and incubated on a shaker at $37{ }^{\circ} \mathrm{C}$ for $2 \mathrm{~h}$ to release any glucuronide conjugates (6). $1 \mathrm{~mL}$ of cold acetonitrile was added to precipitate the proteins present in the serum samples. Urine and serum samples were vortex mixed and centrifuged at 15,000 rpm for $5 \mathrm{~min}$. The supernatants were evaporated to dryness under nitrogen gas. The residues were reconstituted with $200 \mu \mathrm{L}$ of mobile phase, vortex mixed for $30 \mathrm{~s}$, and centrifuged at $15,000 \mathrm{rpm}$ for $5 \mathrm{~min}$. The supernatants were transferred to HPLC vials, and 50 $\mu \mathrm{L}$ of each sample was injected into the HPLC system.

$\beta$-glucuronidase is an enzyme from Escherichia coli type IX-A responsible for breaking the glucuronidated metabolite into the aglycone form.
The amount of aglycone that was not glucuronidated was differentiated from the group to which the enzyme was not added (free sample). The group that underwent enzymatic hydrolysis (total sample) was used to define the amount of the compound that was glucuronidated. The concentration of glucuronidated metabolite was calculated by subtracting the free sample concentration from the total sample concentration $(7,8,9)$.

\section{Pharmacokinetic Analysis}

Phoenix ${ }^{\circledR}$ WinNonlin ${ }^{\circledR}$ software (version 1.0; Pharsight Corporation, Mountain View, CA, USA) was used to analyze the samples and obtain the pharmacokinetic parameters. A non-compartmental model of concentration versus time points was used for data analysis. Specific parameters were applied to determine the half-life $\left(t_{1 / 2}\right)$ and rate of elimination through the software. The log-linear phase of declining concentration versus time plot was used to estimate the apparent decomposition rate constant $(K E)$. The renal clearance $\left(\mathrm{CL}_{\text {renal }}\right)$ was determined by multiplying the fraction of drug excreted unchanged $\left(f_{e}\right)$ with total body clearance $\left(C_{\text {total }}\right)$. Using the equation: $t_{1 / 2}=0.693 / \mathrm{KE}$, the plasma half-life $\left(\mathrm{t}_{1 / 2}\right)$ was calculated. The total amount of calebin A excreted in urine was divided by the total dose administered to estimate the fraction excreted unchanged in the urine $\left(f_{e}\right)$ of calebin $\mathrm{A}$. The renal clearance was calculated by the equation: $C L_{\text {renal }}=f_{e} \times C L_{\text {total }}$

\section{Urine Electrolyte and NAG Analysis}

Urine samples collected in the pharmacokintic study were used to determine urine electrolytes, Cl-, $\mathrm{K}+$ and $\mathrm{Na}+$ using Medica EasyRa automated clinical chemistry analyzer (Medica Corporation Bedford, MA, USA). $25 \mu \mathrm{L}$ of urine samples were diluted with $475 \mu \mathrm{L}$ of Medica EasyLyte Urine Diluent for $\mathrm{Cl}^{-}, \mathrm{K}^{+}$, and $\mathrm{Na}^{+}$analysis. NAG analysis was performed with urine samples from pharmacokinetic study without dilution using Medica EasyRa automated clinical chemistry analyzer (Medica Corporation Bedford, MA, USA).

\section{Pharmacodynamic Studies Antioxidant Capacity Measurement}

The antioxidant capacities of calebin A and curcumin were determined by an assay that depends on inhibiting the oxidation of ABTS ${ }^{\circ}$ (2-2'-Azinodi-[3-ethylbenzthiazoline sulphonate]) to $\mathrm{ABTS}^{+}$ 
by metmyoglobin. The amount of $\mathrm{ABTS}^{\circ+}$ can be measured by spectrophotometry. The extent by which the absorbance is suppressed by calebin A or curcumin is proportional to the concentration of $\mathrm{ABTS}^{\circ+}$. The concentration of $\mathrm{ABTS}^{-+}$is expressed as Trolox equivalents $(\mu \mathrm{g} / \mathrm{mL})$. Stock solutions of calebin A and curcumin were prepared in DMSO at concentations of $1,5,10,50$ and $100 \mu \mathrm{g} / \mathrm{mL}$. No additional dilution was done. In this particular assay, calebin A and curcumin were dissolved in DMSO rather than methanol, which was used for most of the other assays, to prevent any oxidation of methanol by the peroxide working solution. To run the assay, $10 \mu \mathrm{L}$ of sample, $10 \mu \mathrm{L}$ of metmyoglobin and $150 \mu \mathrm{L}$ of chromagen were mixed in a 96-well plate. Following this, $40 \mu \mathrm{L}$ of peroxide working solution was added within $1 \mathrm{~min}$ to all samples. The plate was covered and incubated on a shaker for 5 min at room temperature $\left(25 \pm 1^{\circ} \mathrm{C}\right)$, and the absorbance was measured at $750 \mathrm{~nm}$ using the Synergy HT multiwell plate reader and Gen5 data analysis software (Biotek Instruments Inc., Winooski, VT, USA). The assay was performed in triplicate. More information regarding the assay protocol, can be found in the kit (Antioxidant Assay kit from Cayman Chemical - Cat. no. 709091).

\section{DDP(IV) Inhibition Determination}

A screening of dipeptidyl peptidase IV (DDP (IV)) inhibion was performed based on a fluorescence method. Gly-Pro-Aminomethylcoumarin (AMC) is a fluorogenic substrate used to measure the DDP (IV) activity of calebin A and curcumin when the peptide bonds are cleaved by the action of DDP the free AMC group is released, resulting in a fluorescence that can be detected. Stock solutions of calebin A and curcurmin were prepared in DMSO at concontrations of $0.1,1.0,10.0,50.0$ and 100.0 $\mu \mathrm{g} / \mathrm{mL}$. To run the assay, $10 \mu \mathrm{L}$ of sample was combined with $50 \mu \mathrm{L}$ of diluted substrate solution. The plate was covered and incubated for $30 \mathrm{~min}$ at $37^{\circ} \mathrm{C}$. The fluorescence measurement was performed at an excitation of $340 / 30 \mathrm{~nm}$ and an emission of $460 / 40 \mathrm{~nm}$ using the Synergy HT multiwell plate reader and Gen5 data analysis software (Biotek Instruments Inc., Winooski, VT, USA). The assay was done in triplicate. Inhibition was calculated as $((\mathrm{A}-\mathrm{B}) / \mathrm{A}) \mathrm{x} 100$, where $\mathrm{A}$ was the average fluorescence of the wells containing calebin $\mathrm{A}$ and curcumin. Additional information about the assay protocol can be found in the instruction manual of the kit (DDP (IV) Inhibitor
Screening Assay Kit from Cayman Chemical - Cat. no. 700210).

\section{CYP450 Inhibition Determination}

CYP2C9, CYP3A4, CYP1A2 and CYP2D6 inhibition assays were performed. These assays have the objective to assess metabolism and inhibition of human CYP450 isoenzymes related to hepatic drug metabolism. Vivid $^{\circledR}$ Substrates and CYP450 BACULOSOMES ${ }^{\circledR}$ Plus Reagents were employed. CYP450 BACULOSOMES ${ }^{\circledR}$ Plus Reagents have the advantage in comparison to human liver microsomes that only one CYP450 enzyme is expressed, avoiding metabolism by other CYP450s. A specific CYP450 enzyme metabolizes the Vivid ${ }^{\circledR}$ Substrates into products that are highly fluorescent in aqueous solution. To run the assay, $50 \mu \mathrm{L}$ of Master Pre-Mix was combined with $40 \mu \mathrm{L}$ of the test compound. The plate was incubated for $10 \mathrm{~min}$ at room temperature $\left(25 \pm 1^{\circ} \mathrm{C}\right)$ on a plate shaker. Then, $10 \mu \mathrm{L}$ of Vivid $^{\circledR}$ Substrate was added to each well to start the reaction. Less than $2 \mathrm{~min}$ after the reaction had started, the fluorescence was measured using the Synergy HT multiwell plate reader and Gen5 data analysis software (Biotek Instruments Inc., Winooski, VT, USA). The assay was done in triplicate. The flourecence readings were measured at $1 \mathrm{~min}$ intervals for $60 \mathrm{~min}$. Inhibition was calculated as $(1-(\mathrm{X}-\mathrm{B} / \mathrm{A}-\mathrm{B})) \mathrm{x}$ $100 \%$, where $\mathrm{X}$ was the average fluorescence of the compound, A was the average of solvent control and $B$ was the average of inbition in the presence of positive inhibitor control. Vivid ${ }^{\circledR}$ Substrates, positive inhibitors and excitation/emission wavelengths were different from one assay to another. In CYP2C9 the substrate used was Vivid ${ }^{\circledR}$ BOMF, the positive inhibitor was sulphenazole, and the wavelength settings were $485 / 20 \mathrm{~nm}$ for excitation and $528 / 20 \mathrm{~nm}$ for emission.

In the CYP3A4 assay Vivid $^{\circledR}$ DBOMF Substrate was used, ketoconazole was the positive inhibitor, and the wavelengths for excitation and emission were set at $485 / 20 \mathrm{~nm}$ and of $528 / 20 \mathrm{~nm}$, respectively. In the CYP1A2 assay Vivid $^{\circledR}$ EOMCC Substrate was used, $\alpha$-naphthoflavone was the positive inhibitor, and the wavelength settings for excitation and emission were 415/20 $\mathrm{nm}$ and 460/20 $\mathrm{nm}$ respectively. In the CYP2D6 assay $\mathrm{Vivid}^{\circledR}$ EOMCC Substrate was used, quinidine was the positive inhibitor, and the wavelength settings for excitation and emission were 415/20 nm and $460 / 20 \mathrm{~nm}$, respectively. More information related 
to the assay protocols can be found in the instruction manual of the kits (Vivid ${ }^{\circledR}$ CYP2C9 Green Screening Kit - Cat. no. P2860; Vivid ${ }^{\circledR}$ CYP3A4 Green Screening Kit - Cat. no. P2857; Vivid $^{\circledR}$ CYP1A2 Blue Screening Kit - Cat. no. P2863 and Vivid ${ }^{\circledR}$ CYP2D6 Blue Screening Kit Cat. no. P2972 from Life Technologies).

\section{Cyclooxygenase Inhibition Determination}

A three day commercial assay kit was used to measure the inhibition of COX-1 and COX-2 by calebin $\mathrm{A}$ and curcumin. The assay is based on using a non-specific antibody for prostaglandins (PG) to quantify the prostanoid product using an enzyme immnunoassay (EIA). The concentration of PG tracer is constant whilst the concentration of PG is variable. Therefore, the amount of PG tracer that can bind to the $P G$ antiserum is inversely proportional to the concentration of PGs in the well. Concentrations of 1,10 and $250 \mu \mathrm{g} / \mathrm{mL}$ of calebin A and curcumin were prepared in DMSO. Reagents were prepared according to the manufacturer's instructions. The assay was done in quadruplet. The measurement of absorbance was performed at 415 $\mathrm{nm}$ within $10 \mathrm{~min}$ of the reaction at room temperature using the Synergy HT multiwell plate reader and Gen5 data analysis software (Biotek Instruments Inc., Winooski, VT, USA). Additional information regarding the assay protocol, can be found in the instructions guide of the kit (COX Inhibitor Screening Assay Kit from Cayman Chemical - Cat. no. 560131).

\section{Lipoxygenase Inhibition Determination}

Lipoxygenases are oxidative enzymes responsible for adding a molecular oxygen to fatty acids. The hydroperoxides produced by the reaction are detected and quantified using a purified lipoxygenase. Stock solutions of calebin A and curcumin were prepared in DMSO at concentrations of 1,10 and $250 \mu \mathrm{g} / \mathrm{mL} .10 \mu \mathrm{L}$ of samples were combined with $90 \mu \mathrm{L}$ of lipoxygenase enzyme. $10 \mu \mathrm{L}$ of linoleic acid was added to start the reaction. The plate was covered and placed on a shaker for $5 \mathrm{~min}$. Then, $100 \mu \mathrm{L}$ of chromagen was added. The plate was covered and placed on a shaker for $5 \mathrm{~min}$ again. The assay was done in triplicate. The absorbance was measured at $500 \mathrm{~nm}$ using the Synergy HT multiwell plate reader and Gen5 data analysis software (Biotek Instruments Inc., Winooski, VT, USA). \% Inhibition was calculated using the formula (IA - inhibitor/ IA) $\mathrm{x}$
100 , where IA is the average of absorbance of inital activity. Additional information about the assay protocol can be found in the instruction guide of the kit (Lipoxygenase Inhibitor Screening Assay Kit from Cayman Chemical - Cat. no. 760700).

\section{Content Analysis of Commercial Health Products}

The majority of commercial products obtained were capsules, but there were some tablets as well. Capsule shells were opened and the weight of the powder contents, inside the shell, was recorded. Tablets were crushed until a fine powder form was acheived and the weight was recorded. The fine powders were transferred into $15 \mathrm{~mL}$ centrifuge tubes. $4-6 \mathrm{~mL}$ of methanol was added to each tube for extraction. Tubes were vortex mixed and placed on a shaker for $3 \mathrm{~h}$. Then, they were centrifuged at $2,000 \mathrm{rpm}$ for $5 \mathrm{~min}$. $100 \mu \mathrm{L}$ of supernatant from each extract was collected and aliquoted into 2.0 $\mathrm{mL}$ Eppendorf tubes. $50 \mu \mathrm{L}$ of the internal standard, apigenin, was added to the all samples. Samples were vortex mixed, completly dried under nitrogen gas, and stored at $-20^{\circ} \mathrm{C}$ until analysis. Afterwards, $1 \mathrm{~mL}$ of acetonitrile was added to the samples to precipitate the proteins present in the samples (including the enzyme present in the total samples). Samples were completely dried under nitrogen gas. On the day of analysis, samples were reconstituted in $200 \mu \mathrm{L}$ of the mobile phase and $50 \mu \mathrm{L}$ was injected into HPLC under the same conditions previously described; this analysis procedure was performed twice.

\section{STATISTICAL ANALYSIS}

Data were stastistically analyzed using excel software and were presented as mean and standard error of the mean (mean \pm SEM). Where possible, the data were analyzed for statistical significance with a p-value $<0.05$ being considered statistically significant.

\section{RESULTS}

\section{Chromatography}

The best resolution for calebin A was acheived after several attempts with different acetonitrile and water ratios were carried out. A mobile phase consisting of acetonitrile and water supplemented with $10 \mathrm{mM}$ ammonium formate $\mathrm{pH} 7.0$, at a ratio $40: 60(\mathrm{v} / \mathrm{v})$ and a flow rate of $0.8 \mathrm{~mL} / \mathrm{min}$, 
facilitated adequate separation. Apigenin was chosen as an internal standard after testing several compounds. It had different retention time from calebin A and the solvent, resulting in a good baseline separation between calebin $\mathrm{A}$ and apigenin. The separation of Calebin $\mathrm{A}$ in rat serum urine was accomplished using Kintex ${ }^{\circledR C} 18$ column. Calebin A showed a retention time of $7 \mathrm{~min}$ whereas the retention time for apigenin was $4 \mathrm{~min}$ in both serum and urine blank samples spiked with calebin A and the internal stadard apigenin (Figure 2 and Figure 3). There were no interfering peaks that co-eluted with the compounds of interest in the chromtogram.

Various parameters such as peak shape, linearity and limit of quantitation (LOQ), interference from endogenous substances in biological fluids, stability of reconstituted extracts and freeze-thraw samples, precision and accuracy were used to assess the HPLC assay performance.

\section{Linearity, Limit of Quantitation (LOQ), and Limit of Detection (LOD)}

Serum concentrations of calebin A with a range of $0.001-50 \mu \mathrm{g} / \mathrm{mL}$ demonstrated a linear relationship $\left(r^{2}=0.999\right)$ between the peak area ratio (PAR) of calebin A to the apigenin (Figure 4). From the validation runs in serum the mean regression lines were defined by calebin $\mathrm{A}(\mu \mathrm{g} / \mathrm{mL})=0.0262 \pm$ $0.0207 x-0.0271 \pm 0.014$. Urine concentrations of calebin A within a range of $0.05-50 \mu \mathrm{g} / \mathrm{mL}$ also demonstrated a linear relationship $\left(\mathrm{r}^{2}=0.998\right)$ between PAR of calebin A to the apigenin. Mean regression lines were defined by calebin $\mathrm{A}(\mu \mathrm{g} / \mathrm{mL})$ $=0.0252 \pm 0.0219 \mathrm{x}-0.0197 \pm 0.0017$ from the validation runs in urine. Both matrices presented a LOQ of $0.05 \mu \mathrm{g} / \mathrm{mL}$ and a LOD of $0.0008 \mu \mathrm{g} / \mathrm{mL}$.

\section{Pharmacokinetics of calebin A}

Following administration of calebin A intravenously $(20 \mathrm{mg} / \mathrm{kg})$ and orally $(500 \mathrm{mg} / \mathrm{kg})$, the dispositions of urine and serum were examined. Rapid decline in the serum concentration versus time profile for IV-dosed calebin A was observered in the first hour, representing a distribution phase (Figure 5a) followed by a short elimination phase up to 2 hours. Oral administration of calebin A showed a rapid absorption in the serum with an average $T_{\max }$ of $18 \mathrm{~min}$ (Figure $5 \mathrm{~b}$ ).
Pharmacokinetic parameters of calebin A administered IV at a dose of $20 \mathrm{mg} / \mathrm{kg}$ and $\mathrm{PO}$ at a dose of $500 \mathrm{mg} / \mathrm{kg}$ are summarized in Table 1 . Noncompartmental analysis by WinNonlin software was employed to model both serum and urine data. The total serum clearance of calebin A was found to be $61.0 \pm 41.6 \mathrm{~L} / \mathrm{h} / \mathrm{kg}$ for IV dosing and $11244.3 \pm$ $5258.4 \mathrm{~L} / \mathrm{h} / \mathrm{kg}$ for PO. The mean fraction extracted in urine unchanged (fe) was $0.43 \pm 0.36 \%$ for IV and $0 \%$ for $\mathrm{PO}$, indicating that calebin $\mathrm{A}$ is cleared mainly via non-renal routes. Renal clearance $\left(\mathrm{CL}_{\text {renal }}\right)$ was measured at $0.11 \pm 0.06 \mathrm{~L} / \mathrm{h} / \mathrm{kg}$ for IV and $0.27 \pm 0.24 \mathrm{~L} / \mathrm{h} / \mathrm{kg}$ and hepatic clearance (CL hepatic $\left.=\mathrm{CL}_{\text {total }}-\mathrm{CL}_{\text {renal }}\right)$ was found to be $60.89 \pm$ $41.58 \mathrm{~L} / \mathrm{h} / \mathrm{kg}$ for IV and $11244.00 \pm 5258.16 \mathrm{~L} / \mathrm{h} / \mathrm{kg}$ for PO. The volume of distribution of calebin A was $48.2 \pm 11.8 \mathrm{~L} / \mathrm{kg} \mathrm{IV}$ and $12430.7 \pm 4332.6 \mathrm{~L} / \mathrm{kg}$ for PO. The volume of distribution was greater than the total body water, indicating that calebin A is highly distributed into tissues. The mean area under the curve, which represents the total amount of exposure in the serum over time, was $1.55 \pm 0.74$ $\mathrm{hr} . \mu \mathrm{g} / \mathrm{mL}$ for IV and $0.17 \pm 0.11 \mathrm{~h} \mu \mathrm{g} / \mathrm{mL}$ for PO. The serum concentration of calebin A declined very rapidly with a mean elimination half-life of $3.43 \pm$ $1.83 \mathrm{~h}$ for IV and $1.18 \pm 0.36 \mathrm{~h}$ for PO. The oral bioavailability for calebin A was determined to be $0.46 \%$.

The presence of the parent compound, calebin $\mathrm{A}$ and its glucuronidated metabolite was detected in the analyzed urine samples for both routes of administration. The total cumulative urinary excretion plot indicates that calebin $\mathrm{A}$ is excreted predominantly in the aglycone form for IV administration and in the glucuronidated metabolite form for PO administration (Figure 5c, 5d). The half-life of calebin $\mathrm{A}$ in urine was determined to be $2.07 \pm 1.86 \mathrm{~h}$ for IV. The urinary excretion plots (Figure 5e, 5f) indicates that calebin $\mathrm{A}$ and its glucuronidated metabolite had similar rates of excretion after IV dosing but the glucuronidated metabolite appeared to have a greater rate of excretion compared to the aglycone after PO administration.

The total dose of calebin A administered was $20 \mathrm{mg} / \mathrm{kg}$ for IV and $500 \mathrm{mg} / \mathrm{kg}$ for PO. The average weight of the rats in the experiment was $\sim 300$ g. Therefore, each rat received $\sim 6 \mathrm{mg}$ of calebin A IV and $150 \mathrm{mg}$ PO. 


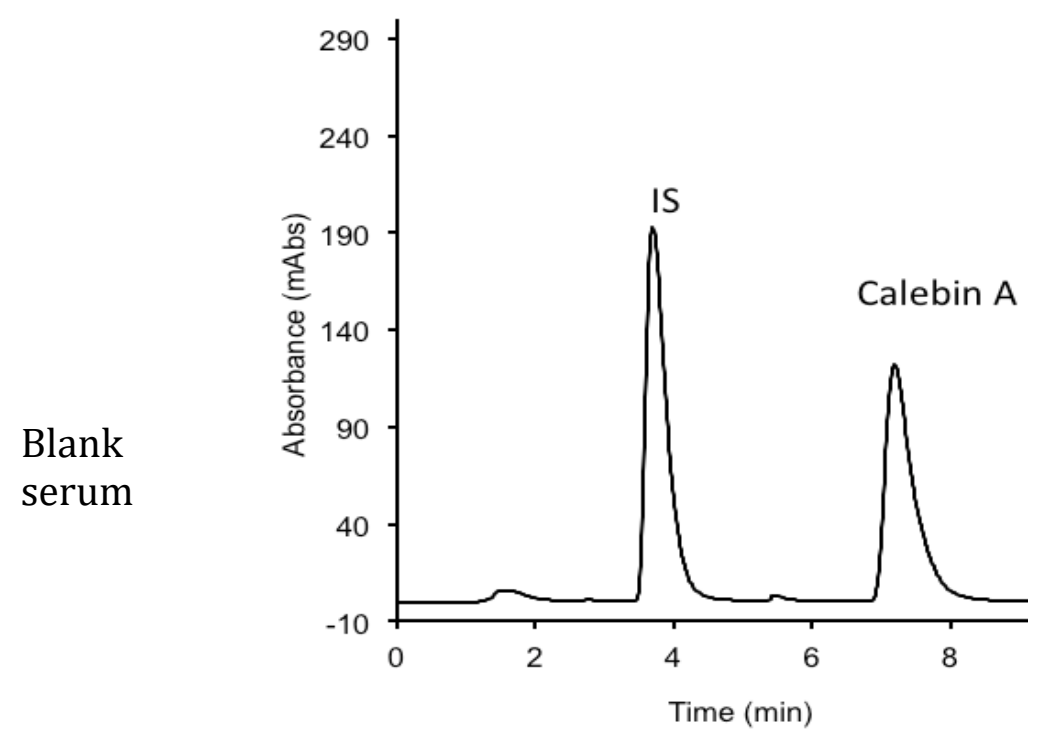

Figure 2. Representative chromatogram of blank rat serum spiked with the IS and calebin A with concentration of 25 $\mu \mathrm{g} / \mathrm{mL}$ demonstrating no interfering peaks that co-eluted with the compounds of interest.

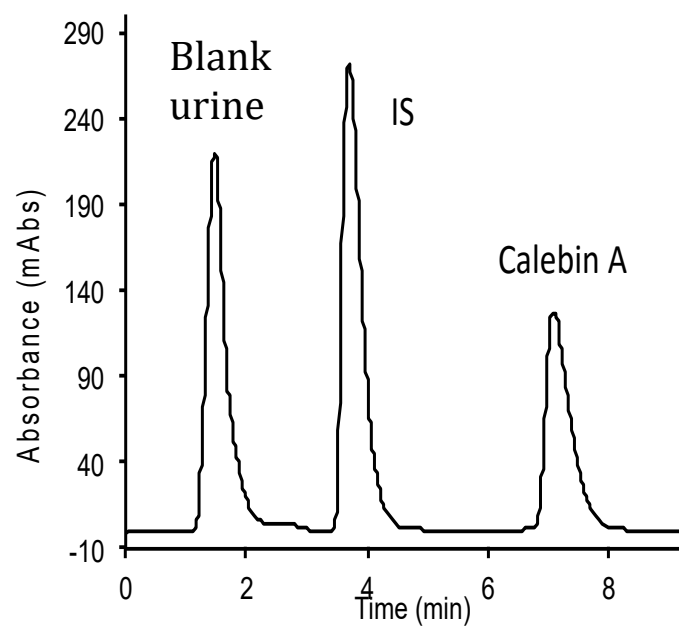

Figure 3. Representative chromatogram of blank rat urine spiked with the IS and calebin A at a concentration of $25 \mu \mathrm{g} / \mathrm{mL}$ demonstrating no interfering peaks that co-eluted with the compounds of interest.

The plots of cumulative amount excreted in urine versus time (Figure 5c,5d) show that the total amount excreted for both the aglycone and glucuronidated forms $(\sim 30 \mu \mathrm{g}$ and $5 \mu \mathrm{g}$, respectively for $\mathrm{IV}$, and $1 \mu \mathrm{g}$ and $6 \mu \mathrm{g}$, respectively for PO) were very small compared to the overall dose administered ( $\sim 6 \mathrm{mg}$ and $150 \mathrm{mg}$ for IV and
$\mathrm{PO}$, respectively). This further indicates that calebin A is eliminated predominantly by non-renal routes. Following IV and PO administration of calebin A, no significant difference was found in NAG and electrolytes excretion (Figure 6). Therefore, this suggests no evidence of kidney injury. 


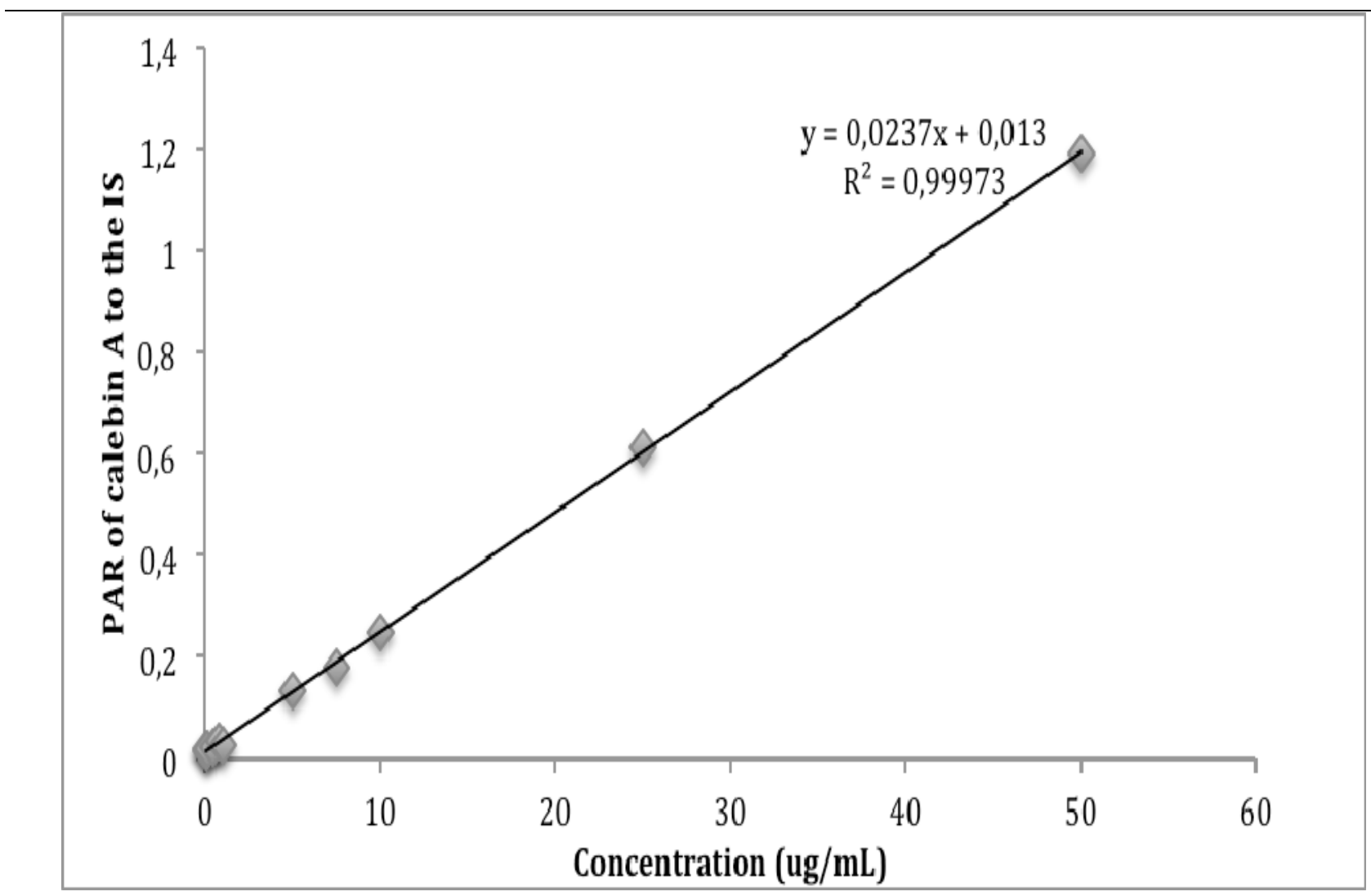

Figure 4. Representative of standard curve illustrating the peak area ratio (PAR) of calebin A to the internal standard (IS) at various concentrations of calebin A added to the serum.

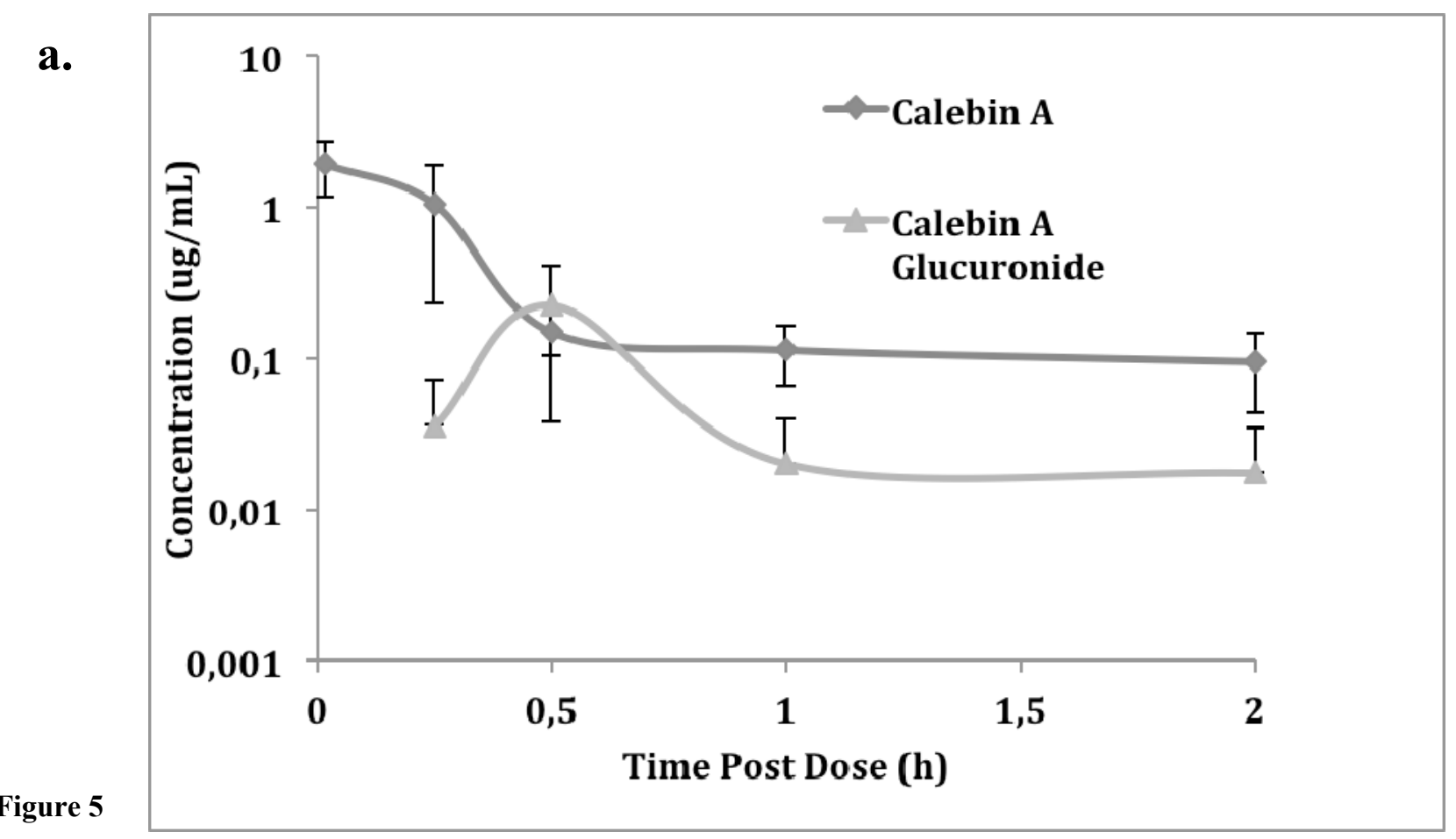


Figure 5 continued.....

b.

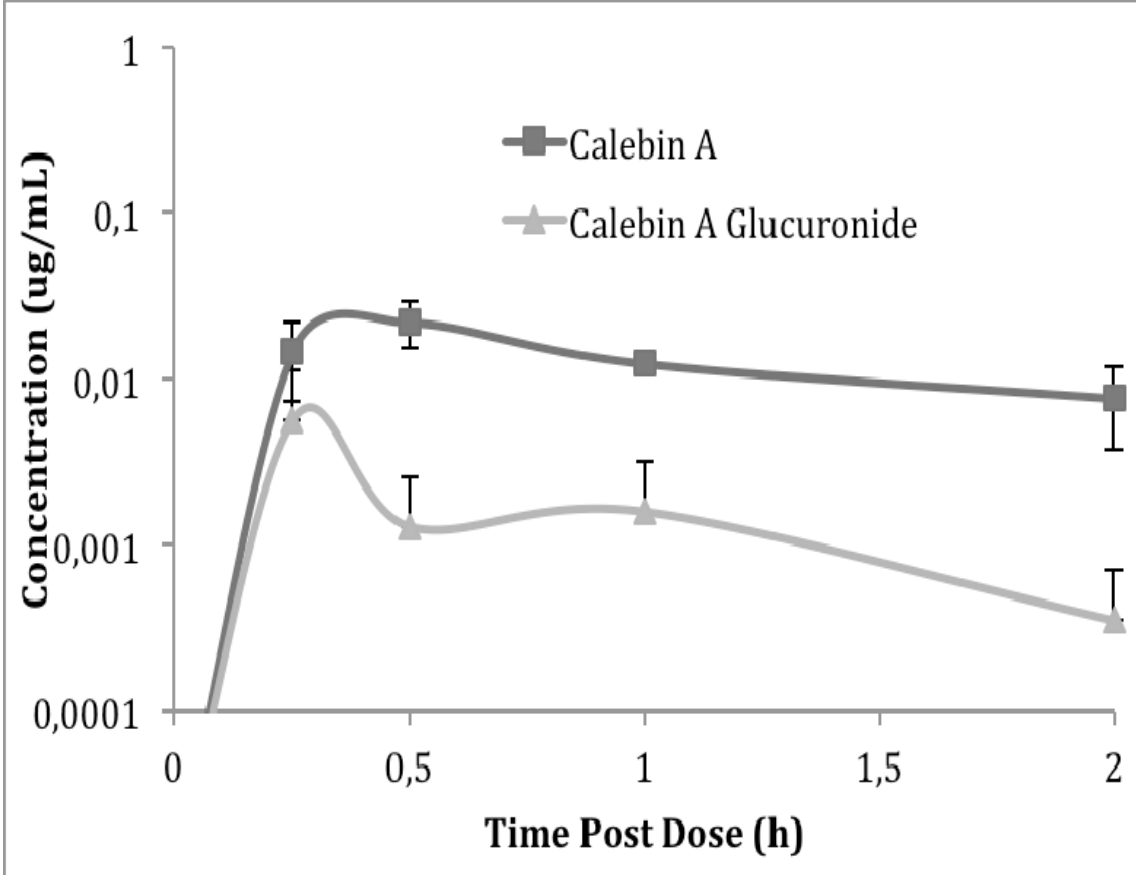

c.

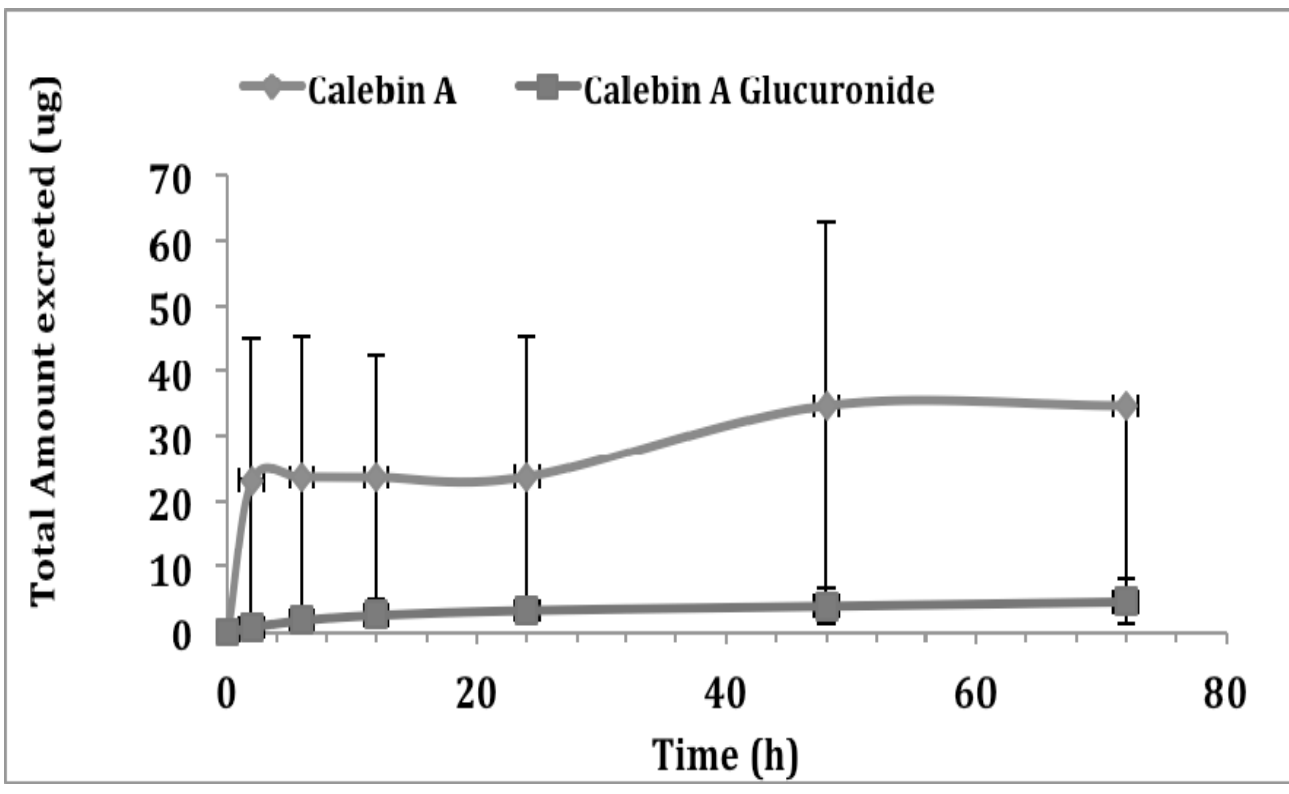


Figure 5 continued.....

d.

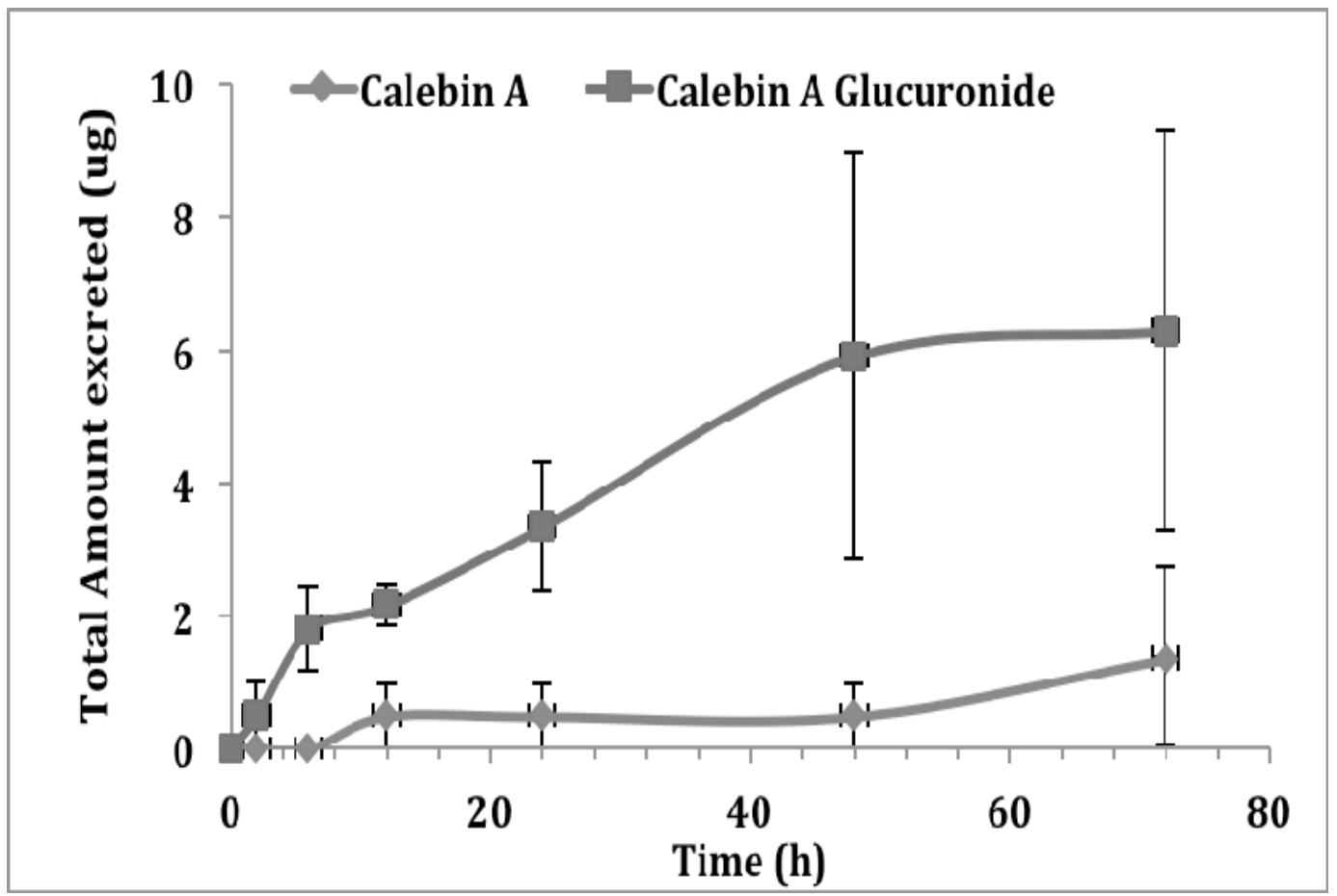

e.

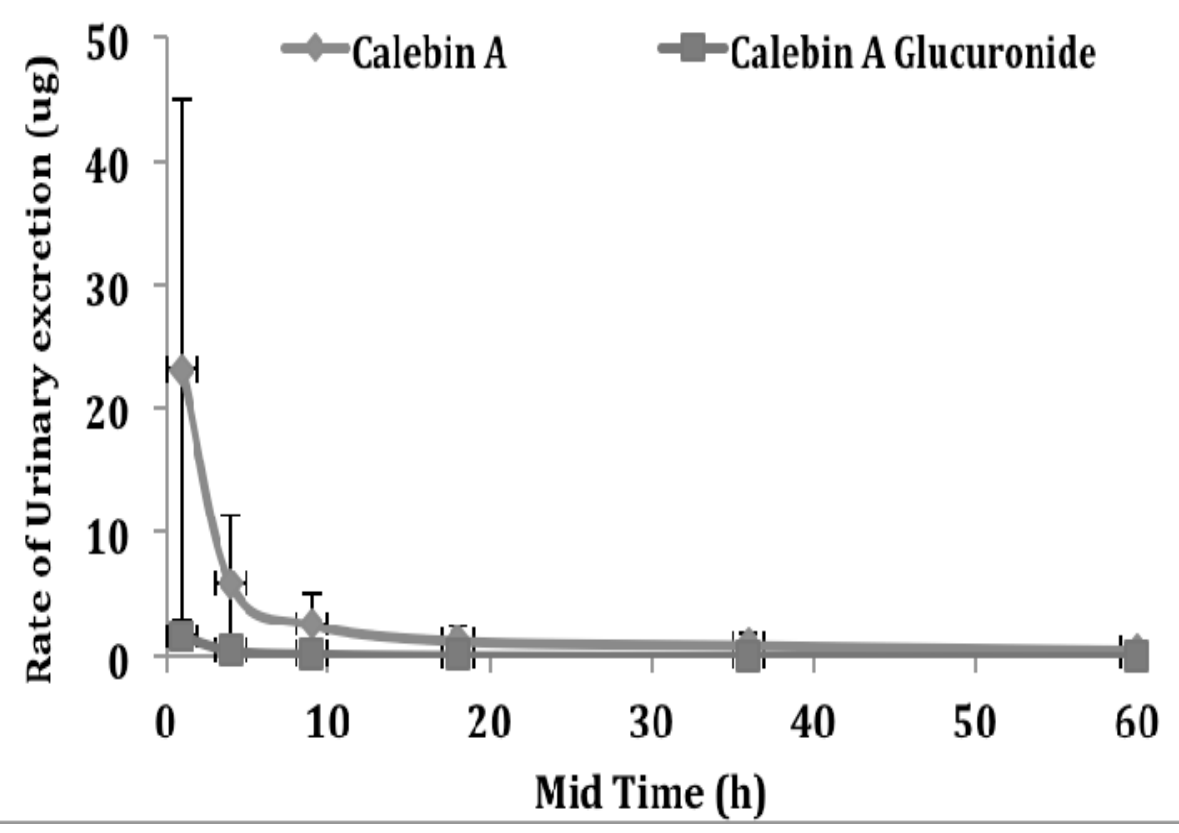


Figure 5 continued.....

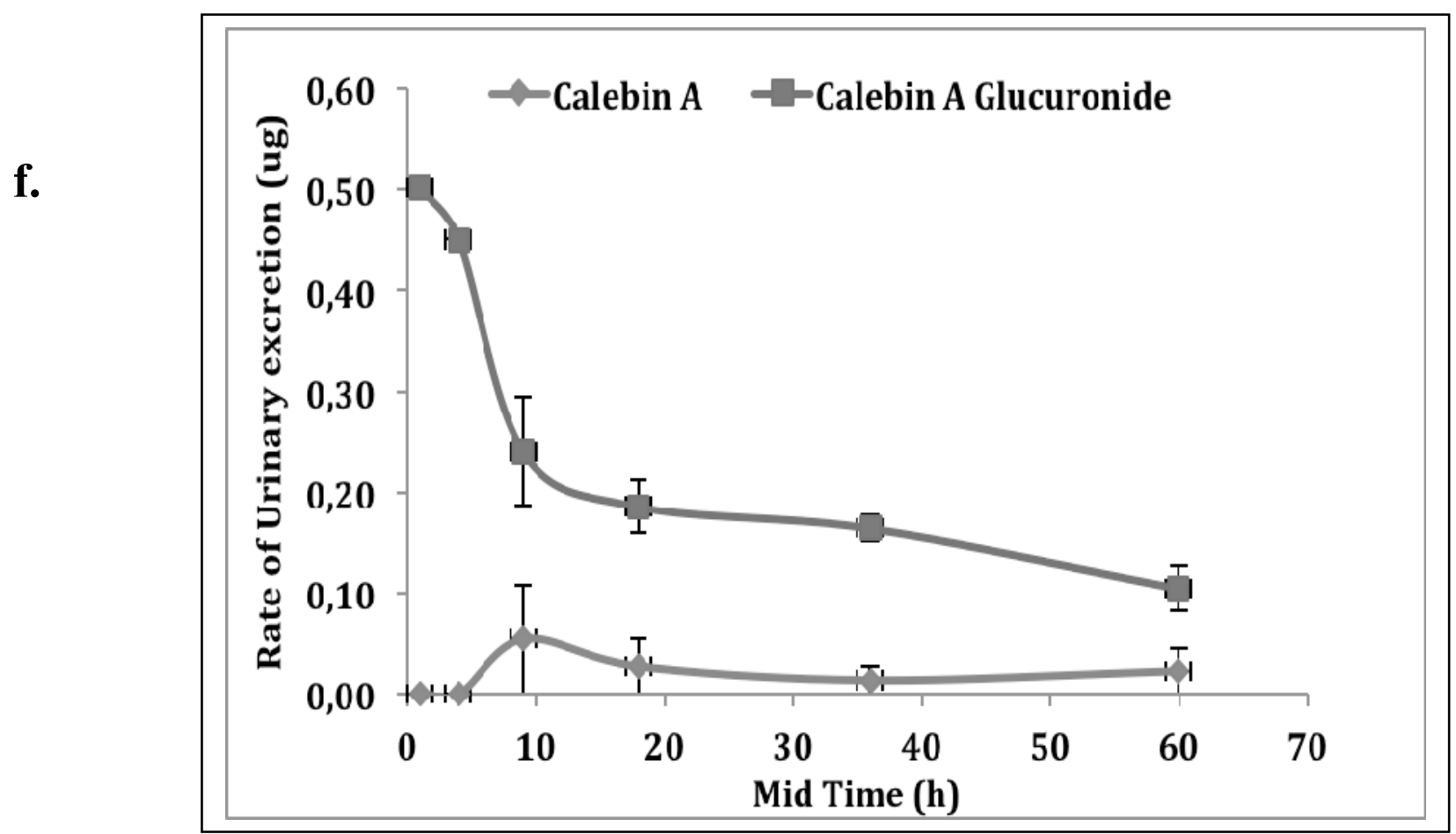

Figure 5. (a) Calebin A disposition in serum following intravenous administration; (b) Calebin A disposition in serum following oral administration; (c) Cumulative calebin A and glucuronidated metabolite ( $\mu \mathrm{g}$ ) excreted in urine over $2 \mathrm{~h}$ after intravenous administration ( $\mathrm{n}=4$ mean \pm SEM); (d) Cumulative calebin A and glucuronidated metabolite ( $\mu \mathrm{g})$ excreted in urine over $2 \mathrm{~h}$ after oral adminstration $(\mathrm{n}=3$ mean $\pm \mathrm{SEM})$; (e) Rate of excretion $(\mu \mathrm{g} / \mathrm{h})$ of calebin A and glucuronidated metabolite in urine over $2 \mathrm{~h}$ after intravenous administration $(\mathrm{n}=4$ mean \pm SEM), ( $\mathrm{f}$ ) Rate of excretion $(\mu \mathrm{g} / \mathrm{h})$ of calebin $\mathrm{A}$ and glucuronidated metabolite in urine over $2 \mathrm{~h}$ after oral administration $(\mathrm{n}=3$ mean \pm SEM)

Table 1. Pharmacokinetic parameters of calebin A in the serum and urine after IV and PO administration in rats ( $\mathrm{n}=4$ mean \pm SEM)

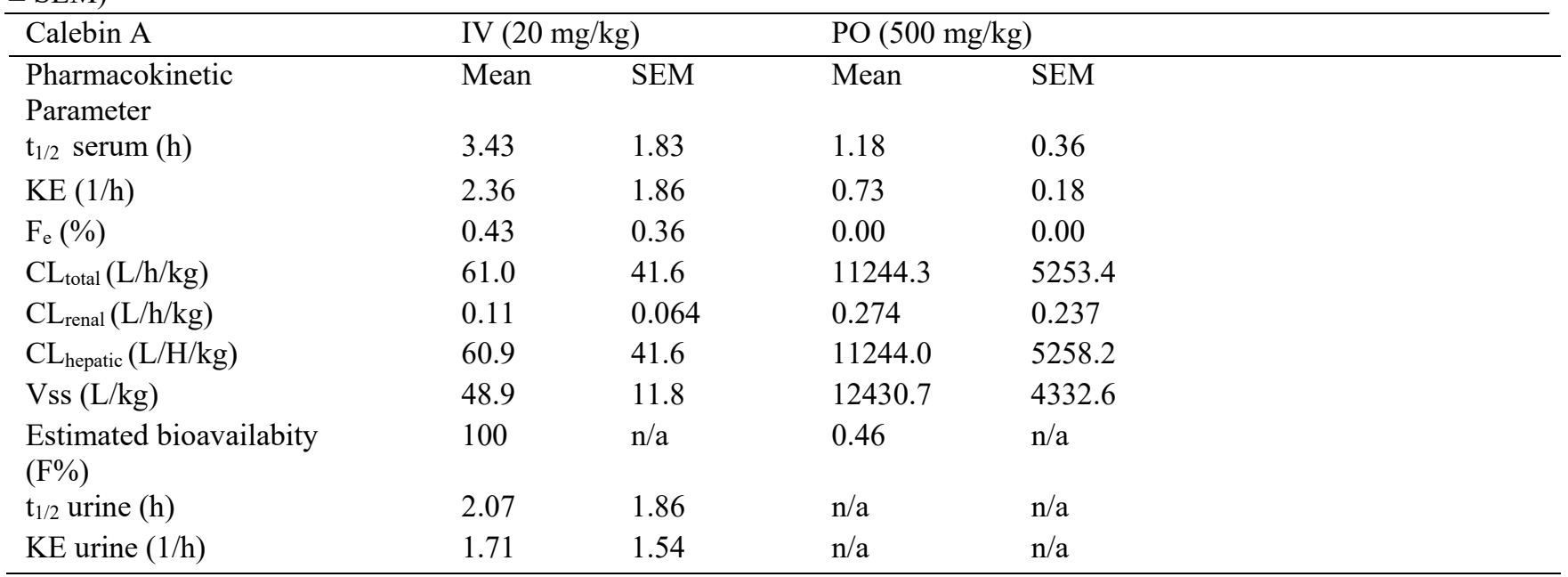


a.

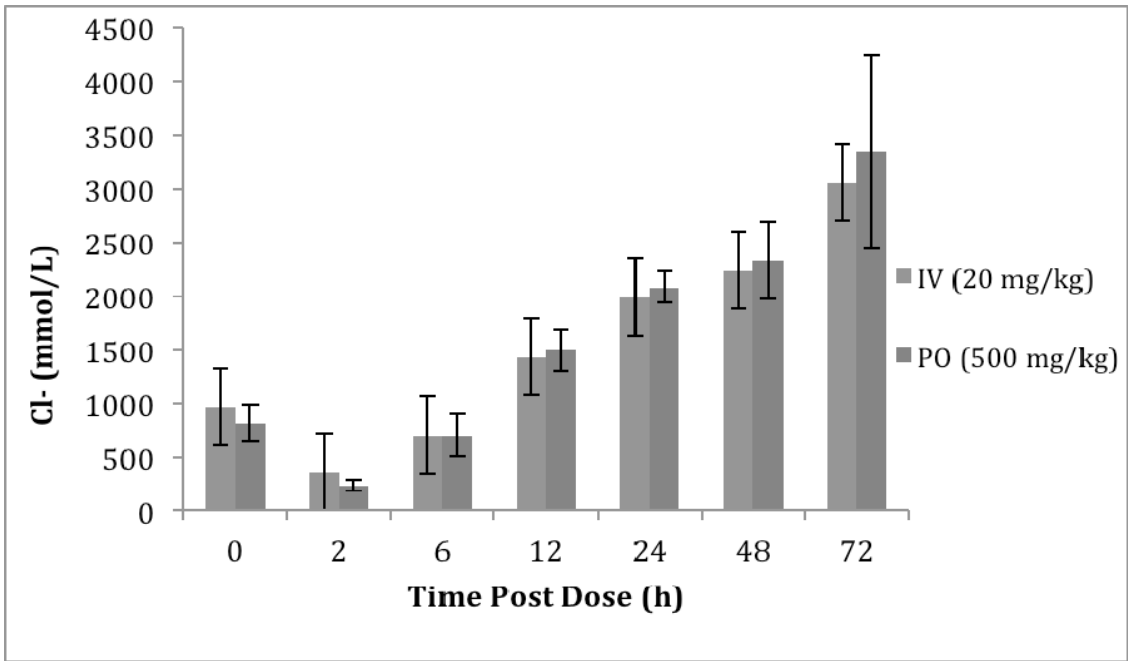

b.

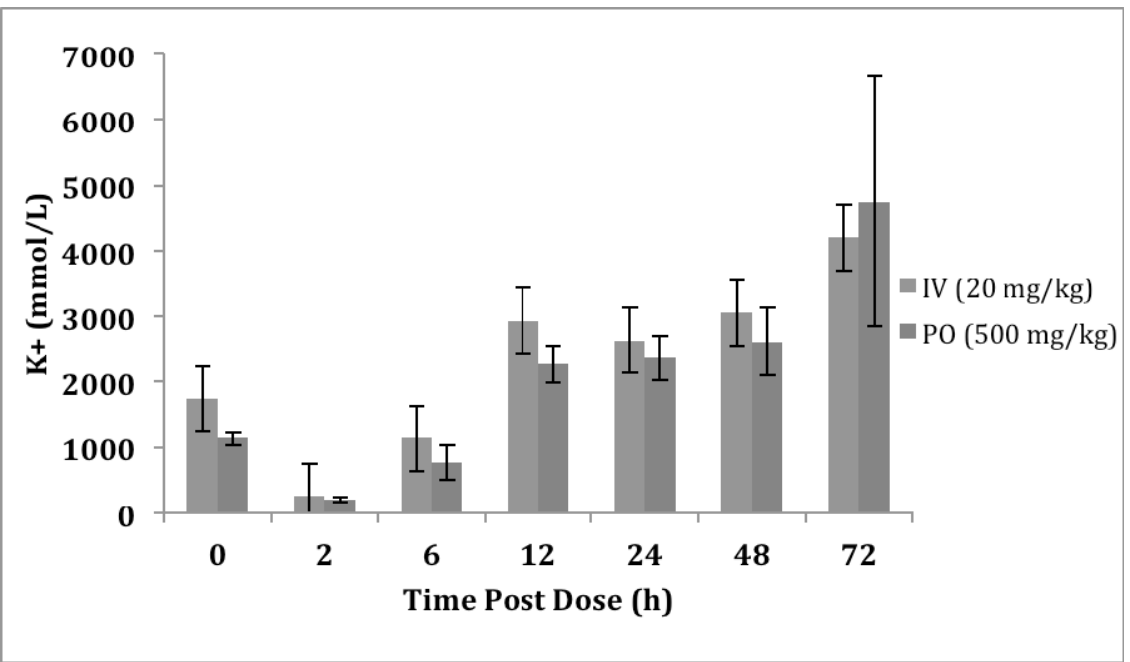

c.

\section{Figure 6}

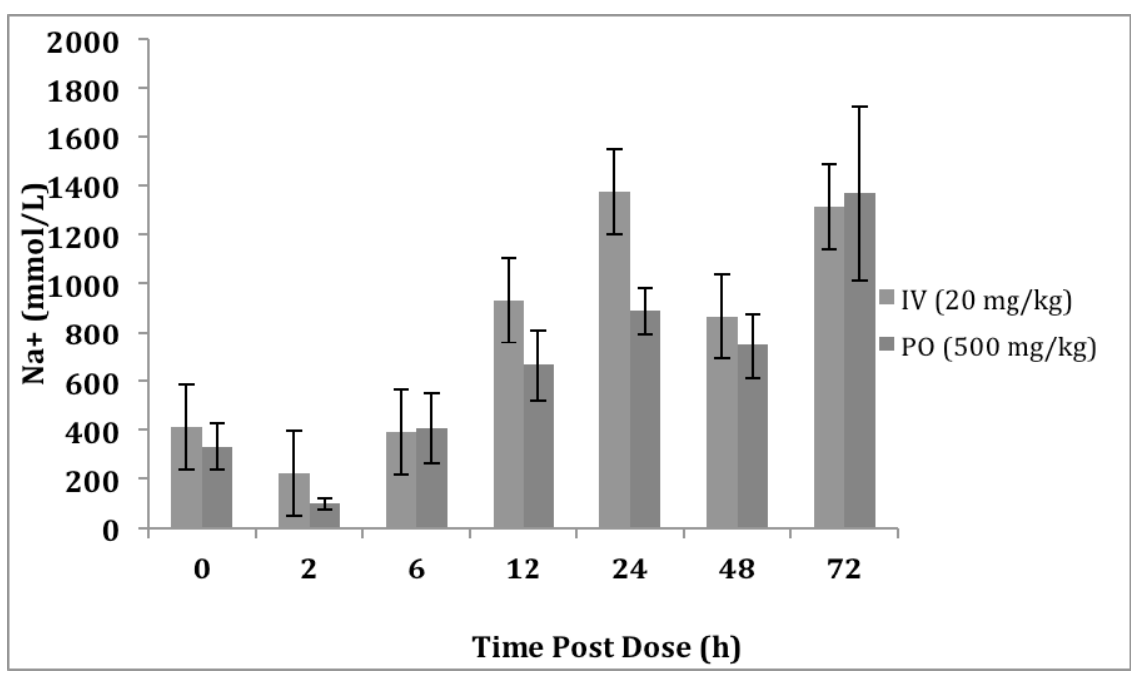


Figure 6 continued.....

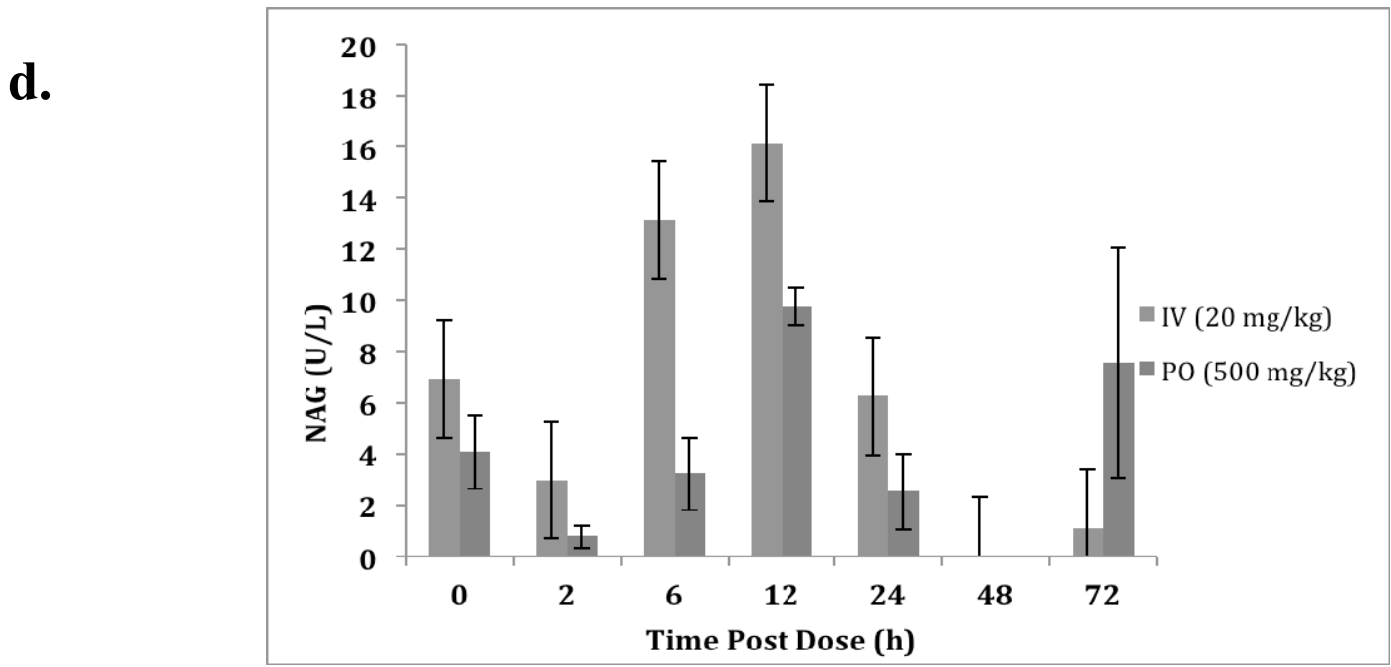

Figure 6. (a) Concentration of $\mathrm{Cl}^{-}(\mathrm{mmol} / \mathrm{L})(\mathrm{n}=4 /$ per group, mean $\pm \mathrm{SEM})$ in urine over $72 \mathrm{~h}$ after intravenous $(20 \mathrm{mg} / \mathrm{kg})$ and oral administration $(500 \mathrm{mg} / \mathrm{kg})$; (b) Concentration of $\mathrm{K}^{+}(\mathrm{mmol} / \mathrm{L})(\mathrm{n}=4 /$ per group, mean $\pm \mathrm{SEM})$ in urine over $72 \mathrm{~h}$ after intravenous $(20 \mathrm{mg} / \mathrm{kg})$ and oral administration $(500 \mathrm{mg} / \mathrm{kg})$; (c) Concentration of $\mathrm{Na}^{+}$(mmol/L) (n=4/per group, mean \pm SEM) in urine over $72 \mathrm{~h}$ after intravenous $(20 \mathrm{mg} / \mathrm{kg}$ ) and oral administration $(500 \mathrm{mg} / \mathrm{kg})$; (d) Concentration of NAG (U/L) ( $=4 /$ per group, mean \pm SEM) in urine over $72 \mathrm{~h}$ after intravenous $(20 \mathrm{mg} / \mathrm{kg})$ and oral administration $(500$ $\mathrm{mg} / \mathrm{kg})$

\section{Pharmacodynamics of Calebin A Cytochrome P450 Inhibition Assays}

Cytochrome P450 are group of metabolic enzymes that are mainly found in the liver. These enzymes are divided into families according to their function. CYP1, CYP2 and CYP3 are the main families related to the oxidative metabolism of drugs (10). In the CYP2C9 screening assay, calebin $A$ and curcumin were shown not to inhibit the enzyme at 0.01 and $0.1 \mu \mathrm{M}$. At $10 \mu \mathrm{M}$ calebin A showed a greater inhibition potential, but at 50 and $100 \mu \mathrm{M}$, curcumin showed greater inhibition activity towards CYP2C9 compared to calebin A (Figure 7a). In the CYP3A4 assay, at concentrations of 0.01 and 10 $\mu \mathrm{M}$ calebin A demonstrated a better inhibitory activity compared to curcumin. At $0.1,1.0,50$ and $100 \mu \mathrm{M}$ concentrations curcumin was a greater inhibitor of CYP3A4 compared to calebin A. At 50 and $100 \mu \mathrm{M}$ curcumin showed a greater inhibition potential compared to assayed concentrations of the positive control ketoconazole $(100 \mu \mathrm{M})$ (Figure $7 \mathrm{~b})$. In the CYP1A2 screening assay, calebin A demonstrated greater inhibitory activity in comparision to curcumin at all tested concencentations (except at $100 \mu \mathrm{M}$, where the mean inhibitory effects were almost the same). At 10 and $50 \mu \mathrm{M}$ calebin A showed greater inhibition potential than assayed concentrations of the positive control $\alpha$-naphthoflavone (Figure 7c). In the CYP2D6 assay, calebin A had greater inhibitory activity in comparison to curcumin at all tested concentrations except at $0.1 \mu \mathrm{M}$ curcumin showed a stronger inhibition effect than calebin A (Figure 7d).

\section{Anti-inflammatory Activity}

Cyclooxygenases (COXs) are enzyme that convert arachidonic acid to prostaglandins. Cyclooxygenases exists in two isoforms: COX-1 (constitutive) and COX-2 (inducible) (11). Studies have demonstrated that curcumin can inhibit prostaglandin synthesis (12). Therefore, to assess the selective COX inhibitory activity for curcumin and calbin $\mathrm{A}$, their $50 \%$ inhibitory concentration $\left(\mathrm{IC}_{50}\right)$ values towards $\mathrm{COX}-1$ and $\mathrm{COX}-2$ were determined. The $\mathrm{IC}_{50}$ values of $\mathrm{COX}-2$ and $\mathrm{COX}-1$ for each compound were used to calculalate the ratio of $\mathrm{IC}_{50}$ of $\mathrm{COX}-2: \mathrm{IC}_{50}$ of $\mathrm{COX}-1$. If the $\mathrm{COX}$ ratio is $>1$, then the compound is a preferential inhibitor of COX-2. If the COX ratio $=$ 1 , then the compound has non-selective antiinflammatory activity towards the two COX isoforms. 
a.

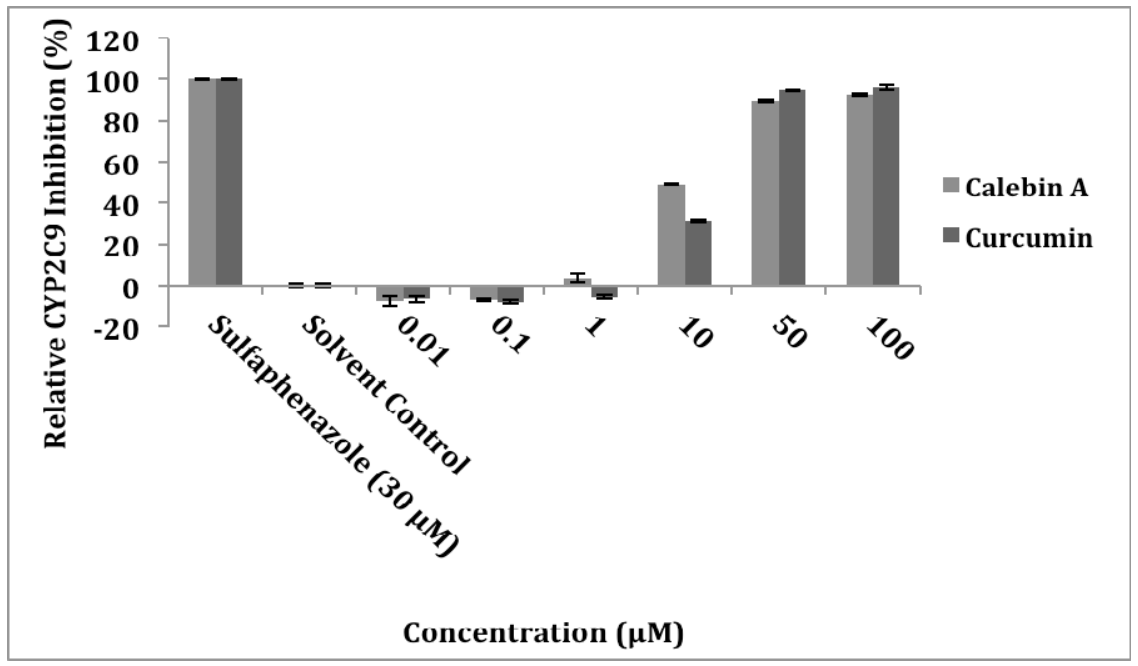

b.

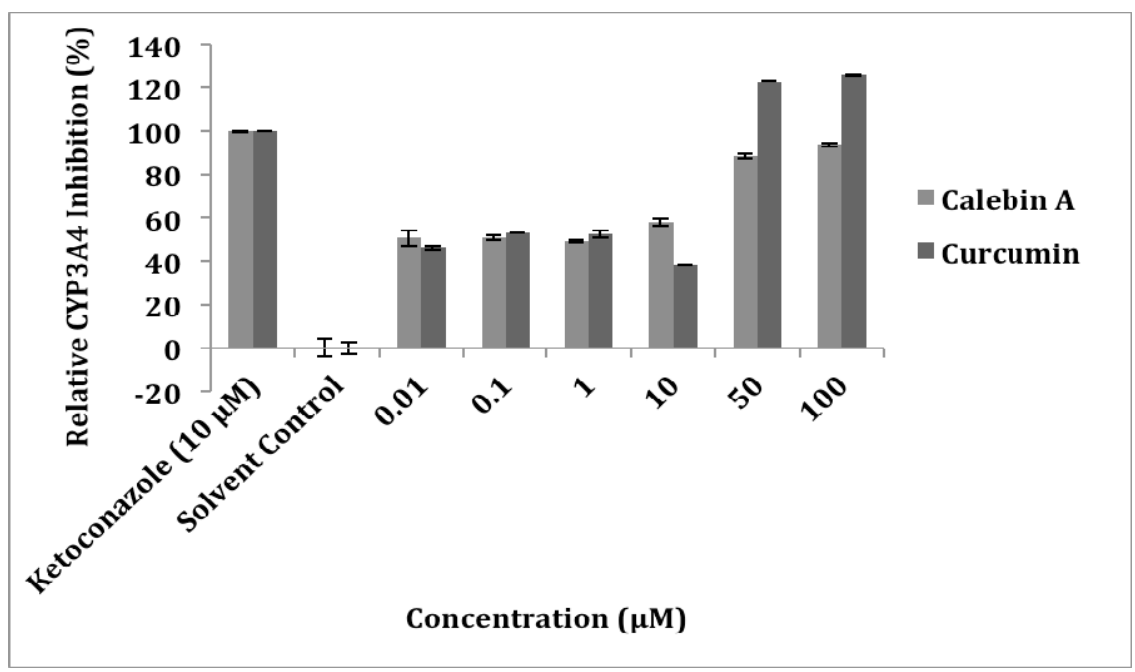

c.

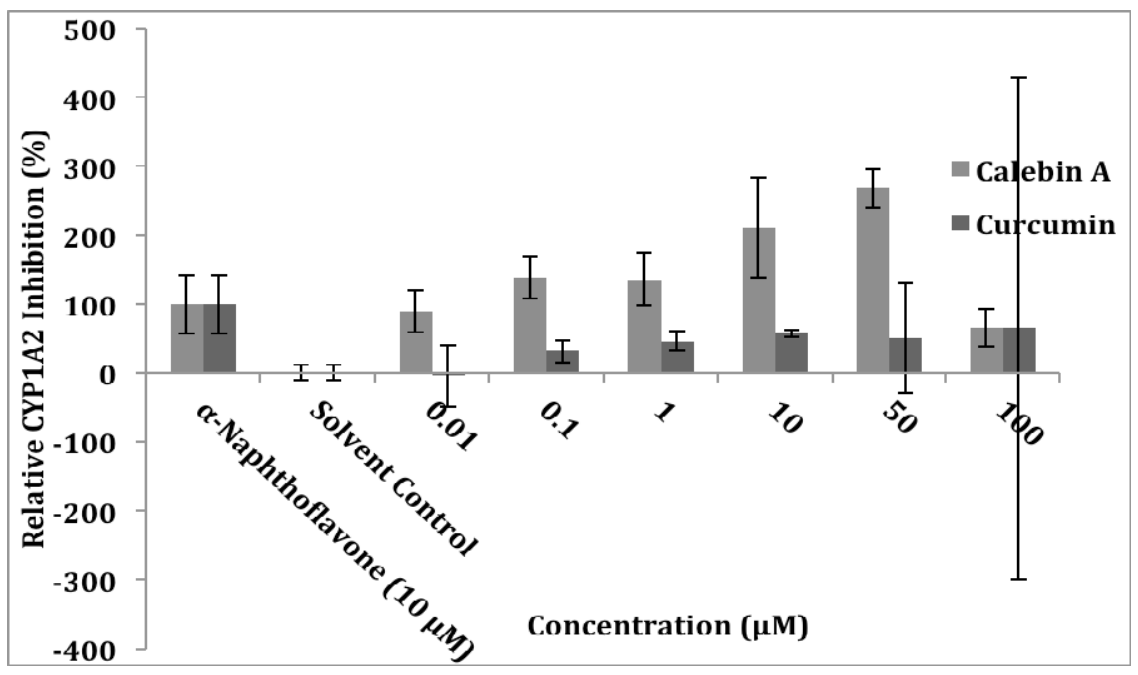

Figure 7. 
Figure 7 continued.....

d.

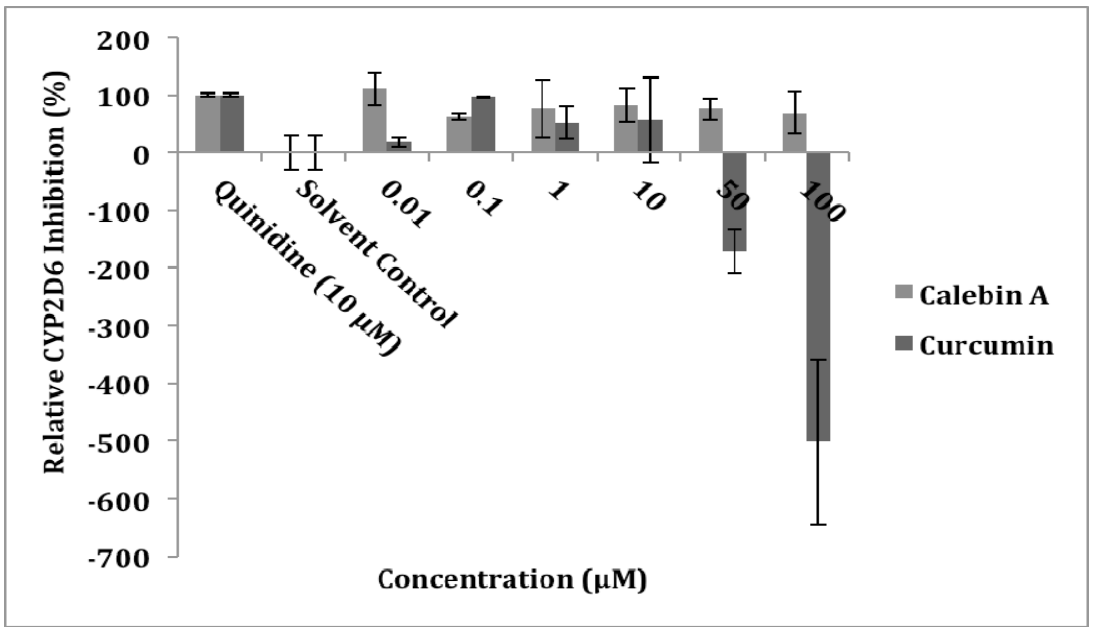

Figure 7. (a) Relative CYP2C9 inhibition $(\%)(n=3$ mean \pm SEM) of calebin A and curcumin at $0.01,0.1,1.0,10.0,50.0$ and $100.0 \mu \mathrm{M}$ dissolved in DMSO; (b) Relative CYP3A4 inhibition (\%)(n=3 mean \pm SEM) of calebin A and curcumin at $0.01,0.1,1.0,10.0,50.0$ and $100.0 \mu \mathrm{M}$ dissolved in DMSO; (c) Relative CYP1A2 inhibition $(\%)(\mathrm{n}=3 \mathrm{mean} \pm \mathrm{SEM})$ of calebin A and curcumin at 0.01, 0.1, 1.0, 10.0, 50.0 and 100.0 $\mu \mathrm{M}$ dissolved in DMSO; (d) Relative CYP2D6 inhibition $(\%)(n=3$ mean \pm SEM $)$ of calebin A and curcumin at 0.01, 0.1, 1.0, 10.0, 50.0 and 100.0 $\mu \mathrm{M}$ dissolved in DMSO

If the COX ratio is $<1$, then the compound is a preferential inhibitor of $\mathrm{COX}-1$. The results show that the ratio of the $\mathrm{IC}_{50}$ of $\mathrm{COX}-2$ to the $\mathrm{IC}_{50}$ of COX-1 for calebin A was close to 1 (Figure 8). Therefore, calebin A has a non-selective antiinflammatory activity. Curcumin has shown a ratio of $\mathrm{IC}_{50}$ of $\mathrm{COX}-2$ to $\mathrm{IC}_{50}$ of COX-1 close to 0.1 . Thus, curcumin has a COX-1 preferential antiinflammatory activity.

Curcumin and calebin A were also assessed for their inhibitory activity towards lipoxygenase. Lipoxygenase converts arachidonic acid to inflammatory leukotrienes, hydroxyeicosatetraenoic acids and lipoxins (mediators of inflammation resolution) (14). Therefore, a compound that inhibits lipoxygenase will exhibit anti-inflammatory activity. Curcumin has shown to be an inhibitor of lipoxygenase. On the other hand, calebin A demonstrated some activity, but its lipoxygenase inhibition was considered poor (Figure 9).

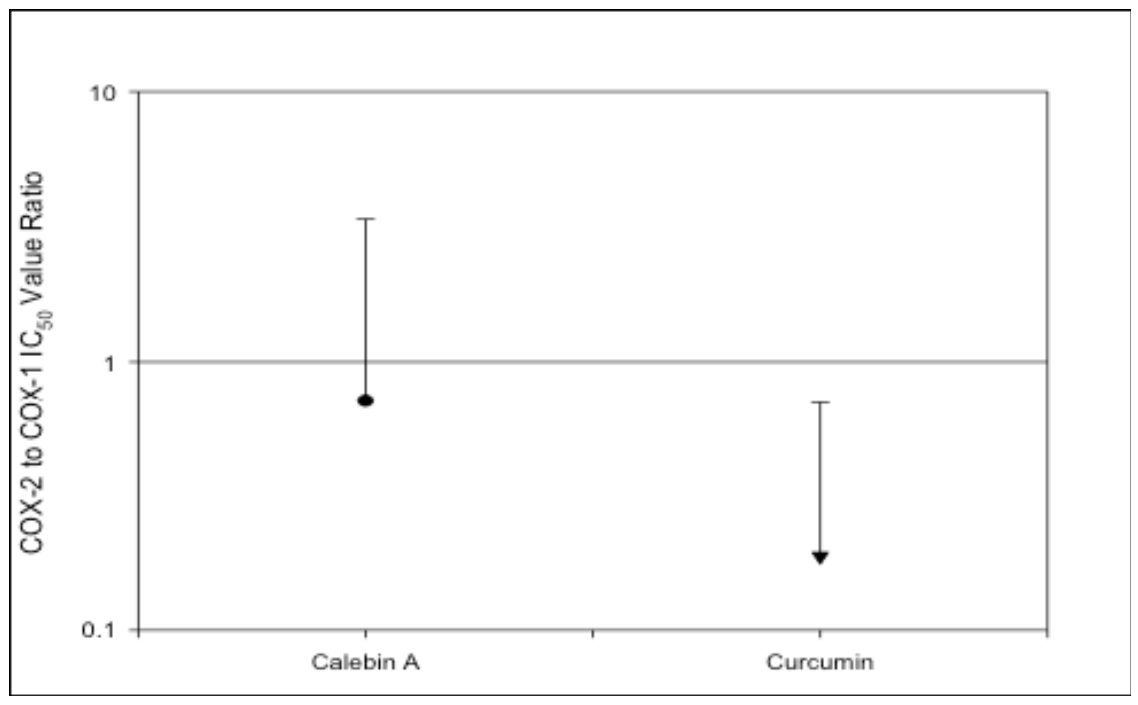

Figure 8. The $\mathrm{IC}_{50}$ of $\mathrm{COX}-2$ : $\mathrm{IC}_{50}$ of $\mathrm{COX}-1 \mathrm{IC}_{50}$ for calebin $\mathrm{A}$ and curcumin 


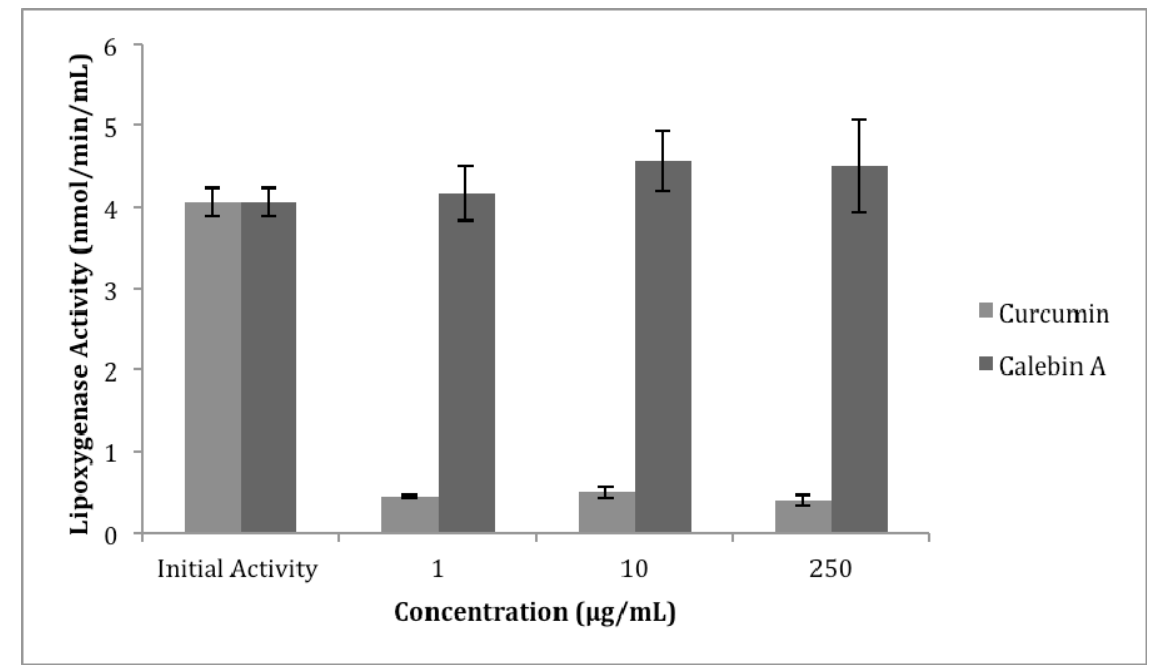

Figure 9. Lipoxygenase activity $(\mathrm{mmol} / \mathrm{min} / \mathrm{mL})(\mathrm{n}=3$ mean \pm SEM) of calebin $\mathrm{A}$ and curcumin at 1,10 and $250(\mu \mathrm{g} / \mathrm{mL})$ dissolved in DMSO

\section{DDP (IV) Inhibition}

Gastric inhibitory polypeptidase (GIP) and Glucagon-like peptide-1 (GLP-1) are hormones responsible for glucose homeostasis. DDP (IV) is the enzyme that controls the secretion of GIP and GLP-1 (13). Curcumin demonstrated a greater inhibitory activity of DDP (IV) compared to calebin A at all the tested concentrations. At high concentrations of curcumin, the percentage of DDP (IV) inhibition was $>100 \%$ (Figure 10).

\section{Antioxidant Activity}

The oxidative stress in cells is related to the pathogenesis of many human diseases due the imbalance between the immune system and oxidants. Antioxidants have the power to bind to free radicals and decrease cellular damage (11). Figure 11 shows the antioxidant activity of calebin $A$ and curcumin in units of Trolox equivalents $(\mu \mathrm{g} / \mathrm{mL})$. The baseline samples (DMSO only) had a low antioxidant capacity $(\sim 0.02 \mu \mathrm{g} / \mathrm{mL})$. The results demonstrate that curcumin exhibited a greater antioxident effect than calebin A. Both calebin A and curcumin showed a greater antioxidant capacity compared to the baseline samples.

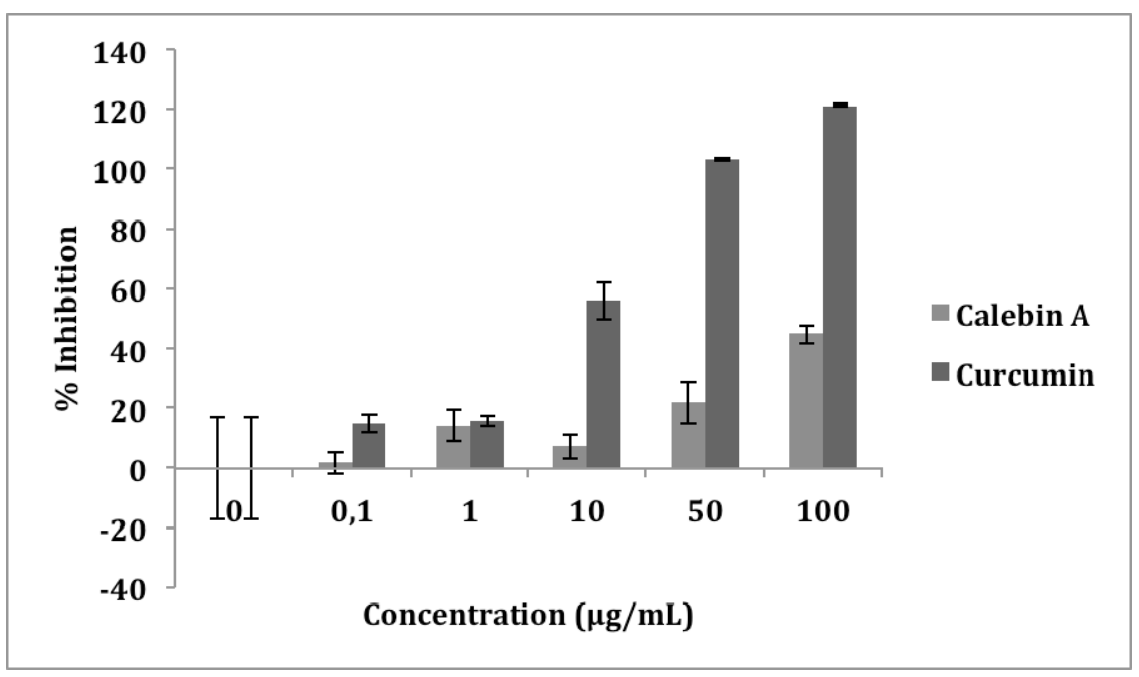

Figure 10. Relative DDP(IV) inhibition (\%)( $\mathrm{n}=3$ mean \pm SEM) of calebin $A$ and curcumin at $0.1,1.0,10.0,50.0$ and 100.0 $\mu \mathrm{g} / \mathrm{mL}$ dissolved in DMSO 


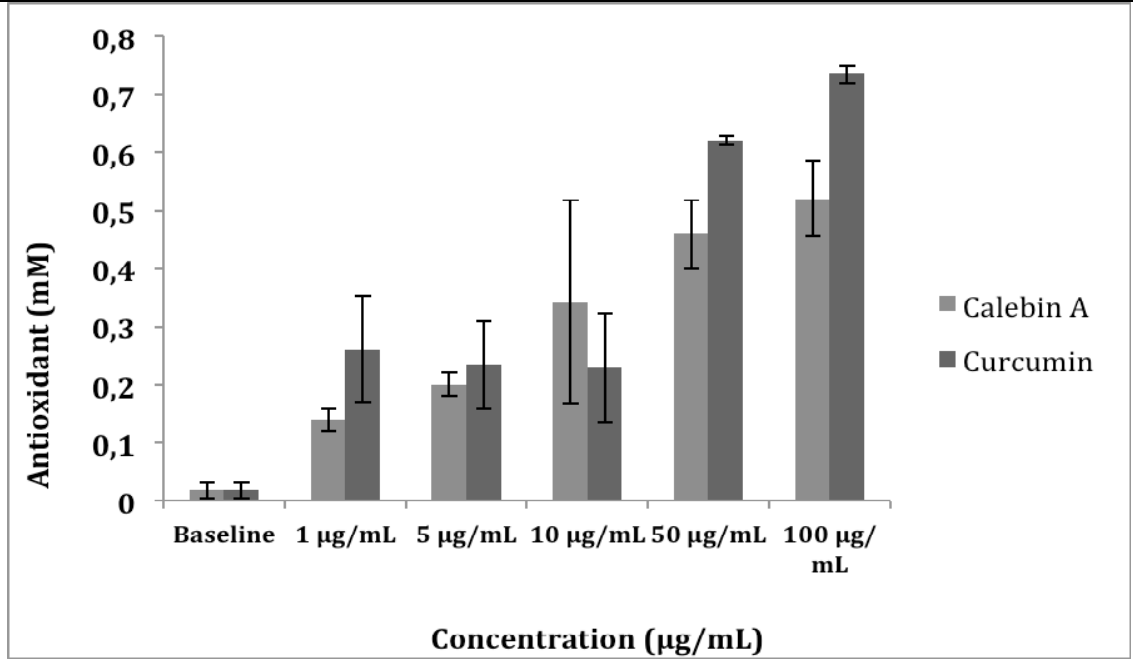

Figure 11. Antioxidant capacity $(\mathrm{n}=3$ mean $\pm \mathrm{SEM}$ ) of calebin A and curcumin at 1.0, 5.0, 10.0, 50.0 and $100.0 \mu \mathrm{g} / \mathrm{mL}$ dissolved in DMSO

\section{Content Analysis of Commercial Health Products}

Table 2 lists the names of the 14 commercial health products that were analyzed for calebin A content. The amount of turmeric claimed on the package of the commercial health product was detected in some products. As previously stated, calebin A is derived from turmeric.

\section{DISCUSSION}

An analytical method for detection and quantification of calebin A using RP-HPLC was developed and validated. No interfering peaks coeluted with calebin A or the internal standard. To our knowledge, this is the first published study on the pharmacokinetics of calebin A in any species. The pharmacokinetic analysis of Calebin A in serum and urine following IV and $\mathrm{PO}$ administration revealed the presence of the parent compound as well as a conjugated metabolite. This indicates that calebin A was orally absorbed and was eliminated through renal and and non-renal routes. Furthermore, the urinary excretion data showed that the mean fraction excreted unchanged in urine $\left(\mathrm{f}_{\mathrm{e}}\right)$ was $0.43 \pm 0.36$ following IV administration of calebin A (Table 1). The IV dose of calebin A was $20 \mathrm{mg} / \mathrm{kg}$, while the PO dose was $500 \mathrm{mg} / \mathrm{kg}$ for a $300 \mathrm{~g}$ rat which translates into a total IV dose of $\sim 6 \mathrm{mg}$ and PO dose of $\sim 150 \mathrm{mg}$ for each animal.Comparing the total amount of calebin A and its glucuronidated metabolite excreted in urine after IV and PO administration shows that $\sim 30 \mu \mathrm{g}$ of the aglycone and $5 \mu \mathrm{g}$ of the glucuronidated metabolite were present in the urine after IV administration compared to $1 \mu \mathrm{g}$ as the aglycone and $6 \mu \mathrm{g}$ as the glucuronidated metabolite after PO administration. Taken together, the results indicate that calebin A is primarily excreted by nonrenal routes. In addition, the high value of hepatic clearance $(60.9 \pm 41.6 \mathrm{~L} / \mathrm{h} / \mathrm{kg}$ for IV and $11244.0 \pm$ $5258.2 \mathrm{~L} / \mathrm{h} / \mathrm{kg}$ for PO) also confirms that caliben A is predominently eliminated via non-renal routes such as hepatic clearance. The urine electrolytes analysis showed that there were no significant differences between electrolytes or NAG excreted in the urine. Thus, no evidence of acute kidney injury was determined. This is consistent with reported studies that indicate the absence of toxic effects of curcumin, even at high doses (up to 5 $\mathrm{g} / \mathrm{kg}$ ) (19). Additionally, the parmacokinetic disposition of calebin A in this study demonstrates that it has a low oral bioavailability $(\sim 0.5 \%)$ and a short half-life $\left(t_{1 / 2}\right.$ urine $\sim 2 \mathrm{~h}$ and $t_{1 / 2}$ serum $\sim 3 \mathrm{~h}$ ) Although there are no published studies delineating pharmacokinetics of calebin $\mathrm{A}$, the poor bioavailability of curcumin in rodents has been stated in previous pharmacokinetics studies $(15,16$, 17). Factors contributing to the poor bioavailability of curcumin are poor solubility and absorption coupled with its rapid metabolic elimination through reduction and conjugation reactions which limits calebin A's systemic exposure. $(15,18)$. 
Table 2. Amount $( \pm$ SD) of calebin A in 14 commercial health products.

\begin{tabular}{|c|c|c|c|}
\hline Product & Claimed amount on package & Amount of Turmeric claimed & Calebin A $(\mu \mathrm{g})$ \\
\hline $\begin{array}{l}\text { ProCreation Female } \\
\text { Fertility Support }\end{array}$ & 60 capsules & 2 capsules - Turmeric $50 \mathrm{mg}$ & $4.864( \pm 1.11)$ \\
\hline OM3 Memory & 30 capsules $-250 \mathrm{mg}$ & 1 capsule - Turmeric $27.5 \mathrm{mg}$ & $3.319( \pm 0.277)$ \\
\hline QTABS Herbal Clean & 10 tablets & & $5.149( \pm 0.501)$ \\
\hline $\begin{array}{l}\text { CanPrev Digestion \& } \\
\text { IBS }\end{array}$ & 120 capsules & 1 capsule - Curcumin $31 \mathrm{mg}$ & $8.904( \pm 6.21)$ \\
\hline $\begin{array}{l}\text { Himalaia Herbal } \\
\text { Healthcare, } \\
\text { DermaCare }\end{array}$ & 120 capsules & & $3.453( \pm 0.310)$ \\
\hline $\begin{array}{l}\text { HerbalFactors, Liv- } \\
\text { Gall Cleanse }\end{array}$ & 90 capsules & $\begin{array}{l}1 \text { capsule - Turmeric } 50 \mathrm{mg} \text {; } \\
\text { Curcuminoids } 5 \mathrm{mg}\end{array}$ & $7.185( \pm 1.64)$ \\
\hline $\begin{array}{l}\text { Planetary Herbals, } \\
\text { Myelin Sheath Support }\end{array}$ & 90 tablets $-820 \mathrm{mg}$ & & $2.732( \pm 0.444)$ \\
\hline $\begin{array}{l}\text { Turmeric Ginger Joint } \\
\text { Ease }\end{array}$ & 100 capsules & 4 capsules - Turmeric $1.3 \mathrm{~g}$ & $54.157( \pm 10.4)$ \\
\hline $\begin{array}{l}\text { Nature's Bounty } \\
\text { Turmeric }\end{array}$ & 60 capsules $-450 \mathrm{mg}$ & $\begin{array}{l}1 \text { capsule - Turmeric } 450 \mathrm{mg} \text {; } \\
\text { Turmeric Extract } 50 \mathrm{mg}\end{array}$ & $6.994( \pm 0.524)$ \\
\hline $\begin{array}{l}\text { Himalaia Herbal } \\
\text { Healthcare HemoCare }\end{array}$ & 120 capsules & & $2.521( \pm 0.107)$ \\
\hline $\begin{array}{l}\text { MacroLife Naturals, } \\
\text { Miracle Reds }\end{array}$ & $56,7 \mathrm{~g}$ & & $3.414( \pm 0.078)$ \\
\hline Turmeric Curcumin & 60 capsules $-300 \mathrm{mg}$ & 1 capsule -Turmeric $300 \mathrm{mg}$ & $10.658( \pm 5.40)$ \\
\hline $\begin{array}{l}\text { Zand, Decongest } \\
\text { Herbal }\end{array}$ & 48 capsules & 2 capsules - Turmeric $45 \mathrm{mg}$ & $3.234( \pm 0.430)$ \\
\hline $\begin{array}{l}\text { Planetary Herbals, } \\
\text { Stone Free }\end{array}$ & 90 tablets $-820 \mathrm{mg}$ & & $5.766( \pm 0.251)$ \\
\hline
\end{tabular}

Likewise, there are no reported studies on the pharmacological activities of calebin A; however, there are studies examining the pharmacological effects of curcumin. Recent evidence has shown that curcumin exhibits anti-inflammatory activity through several pathways. Curcumin inhibits COX2, LOX, iNOS, production of cytokines, and also the activation of transcription factors (11). Conversely, our study revealed that curcumin is a COX-1 inhibitor and that calebin $\mathrm{A}$ is a nonselective COX inhibitor. Published studies in the literature have linked the anti-diabetic potential of curcumin with its anti-inflammatory and antioxidant properties (24). In this study, the antidiabetic activity of curcumin and calebin A were analyzed via their potential to inhibit DDP(IV). Although calebin A was shown to be a poor inhibitor of DDP(IV) curcumin demonstrated that it has superior inhibition properties towards DDP(IV) compared to calebin A. Addtionally, many studies have stated that curcumin has potential antioxidant activity $(11,21-23)$. Metabolic dysfunctions and altered pathophysiology and disease conditions such as inflammation, atherosclerosis, arthritis, cancer, Alzeihmer's diseases all involve oxidative stress (11). Given that calebin A and curcumin were shown to exhibit dose-dependent antioxidant effects calebin A and curcumin may play a role in the management of conditions with a component of oxidative stress. Curcuminoids have demonstrated potential inhibitory activities towards many human drug metabolizing enzymes of the CYP family. Curcumin was found to be an inhibitor of CYP3A4 and demethoxycurcumin has been observed to be an inhibitor of CYP2C9 (20). In this present study, calebin A was also found to inhibit CYP1A2 and CYP2D6 in vitro although no clinical studies have been conducted as to the relevance of this finding.

Finally, the evaluation of the methanolic extracts of selected comercially available products yielded detection of calebin A in all screened health products in this study. Despite some variability between products, it was possible to detect the compound in all the commercial health products investigated. The variability in the content of 
calebin A between products may be due the lack of standarized methods for analysis and quantification of commercial health products on the market.

\section{CONCLUSION}

In summary, an assay was developed for the detection of calebin A in commercial health products using RP-HPLC. Preliminary pharmacokinetic studies indicate that calebin $\mathrm{A}$ has poor oral bioavailability, a short half-life of $\sim 2$ hand is primarly cleared by non-renal mechanisms. Calebin A dosed orally and intravenously in rats resulted in the formation of glucuronidated metabolites. Calebin A appears to exhibit a variety of pharmacological activities and has the ability to inhibit CYPs similar to curcumin. The compound showed an antioxidant capacity that was equal to curcumin and a DDP IV inhibition potential that was lower than curcumin. Calebin A appears to be a non-selective cyclooxygenase inhibitor and also a poor lipoxygenase inhibitor. Calebin A was found in all turmeric-contaning natural health products that were investigated. Studies are onging in our laboratory to further characterize the pharmacokinetics and determine the bioactivity of calebin A and related compounds.

\section{ACKNOWLEDGMENTS}

The authors would like to thank Sabinsa Corporation for an unrestricted grant and the Brazilian National Council for Scientific and Technological Development (CNPq) for their support. Acknowledgments are also extended to Kuwait University for graduate scholarship awarded to Samaa Alrushaid.

\section{REFERENCES}

1. Kim D, Kim J. Total synthesis of Calebin A, preparation of its analogues, and their neuronal cell protectivity against beta-amyloid insult. Bioorg Med Chem Lett. 2001 Sept 17; 11: 2541-2543

2. Li Y, Li S, Han Y, Liu J, Zhang J, Li F, Wang Y, Liu X, Yao L. Calebin-A induces apoptosis and modulates MAPK family activity in drug resistant human gastric cancer cells. Eur J Pharmacol. 2008 Sept 4; 591: 252-258

3. Araujo CC, Leon LL. Biological Activities of Curcuma longa L. Mem Ins Oswaldo Cruz [Internet]. 2001; 96 (5): 723-728. Available from: http://www.ncbi.nlm.nih.gov/pubmed/11500779
4. Aggarwal B, Yuan W, Li S, Gupta S. Curcumin-free turmeric exhibits anti-inflammatory and anticancer activities: identification of novel components of turmeric. Mol Nutr Food Res. 2013 Sept; 57: 19291942.

5. Grupta SC, Sung B, Kim JH, Prasad S et al. Multitargeting by turmeric, the golden spice: from kitchen to clinic. Mol Nutr Food Res [Internet]. 2013 Sept; 57: 1510-1528. Available from: http://www.ncbi.nlm.nih.gov/pubmed/22887802

6. Yang C, Y, Tsai SY, Chao PDL, Yen HF, Chien TM, Hsiu SL. Determination of hesperetin and its conjugate metabolites in serum and urine. J Food Drud Anal [Internet]. 2002; 10 (3): 143-148. Available from: http:/www.fda.gov.tw/en/ publishJFDAListContent.aspx $\mathrm{id}=28 \& \mathrm{chk}=93 \mathrm{a} 9 \mathrm{ab} 8$ 3-afea-436f-96a6-5bf6057f23ad\&param $=$ pn $\% 3 D 83$ $\% 26 \mathrm{cid} \% 3 \mathrm{D}$

7. Roupe KA, Remsberg CM, Yañez JA, Davies NM. Pharmacometrics of stilbenes: segueing towards the clinic. Curr Clin Pharmcol [Internet]. 2006 Jan; 1 (1): 81-101. Available from: http://www.ncbi.nlm.nih.gov/pubmed/18666380

8. Roupe KA, Yañes JA, Teng XW, Davies NM. Pharmacokinetics of selected stilbenes: rhapontigenin, piceatannol and pinosylvin in rats. $\mathrm{J}$ Pharm Pharmacol [Internet]. 2006 Nov; 58 (11): 1443-1450. Available from: http://www.ncbi.nlm.nih.gov/pubmed/17132206

9. Martinez SE, Sayre CL, Davies NM. Analysis of 3methoxypterostilbene in biological fluids by highperformance liquid chromatography: application to pre-clinical pharmacokinetics. Biomed Chromatogr. 2013; 27: 67-72

10. Gardiner SJ, Begg EJ. Pharmacogenetics, drugmetabolizing enzymes, and clinical practice. Pharmacol Rev [Internet]. 2006 Sep;58(3):521-90. Available from: http://www.ncbi.nlm.nih.gov/pubmed/16968950

11. Menon VP, Sudheer AR. Antioxidant and antiinflammatory properties of curcumin. Adv Exp Med Biol [Internet]. 2007; 595: 105-125. Available from: http://www.ncbi.nlm.nih.gov/pubmed/17569207

12. Huang MY, Lysz T, Ferraro T, Abidi TF, Laskin JD, Conney AH. Inhibitory effects of curcumin on in vitro lipoxygenase and cyclooxygenase activities in mouse epidermis. Cancer Res [Internet]. 1991; 51: 813-819. Available from: http://www.ncbi.nlm.nih.gov/pubmed/1899046

13. Godinho R, Mega C, Teixeira-de-Lemos E, Teixeira F, Fernandes R, Reis F. The place of dipeptidyl peptidase-4 inhibitors in Type 2 Diabetes therapeutics: A "Me too" or "The Special One" antidiabetic class? J Diabetes Res [Internet]. 2015: 806979. Available from: http://www.hindawi.com/journals/jdr/2015/806979/ 
14. Hwang SH, Wecksler AT, Wagner K, Hammock BD. Rationally designed multitarget agents against inflammation and pain. Curr Med Chem [Internet]. 2013, 20 (13): 1783-1799. Available from: http://www.ncbi.nlm.nih.gov/pubmed/23410172

15. Zhonga L, Chiu M, Wang J, Chen W, Yen W, FanHarvard P, Yee LD, Chan KK. Enhancement of curcumin oral absorption and pharmacokinetics of curcuminoids and curcumin metabolites in mice. Cancer Chemother Pharmacol [Internet]. 2012 Mar; 69 (3): 679-689. Available from: http://www.ncbi.nlm.nih.gov/pubmed/21968952

16. Pan MH, Huang TM, Lin JK. Biotransformation of curcumin through reduction and glucuronidation in mice. Drug Metab Dispos Biol Fate Chem [Internet]. 1999 Apr; 27: 486-494. Available from: http://www.ncbi.nlm.nih.gov/pubmed/10101144

17. Vareed SK, Kakarala M, Ruffin MT, Crowell JA, Normolle DP, Djuric Z, Brenner DE. Pharmacokinetics of curcumin conjugate metabolites in health human subjects. Cancer Epidemiol Biomarkers Prev [Internet]. 2008 Jun; 17: 14111417. Available from: http://www.ncbi.nlm.nih.gov/pubmed/18559556

18. Lopez-Lazaro M. Anticancer and carcinogenic properties of curcumin considerations for its clinical development as a cancer chemopreventive and chemotherapeutic agent. Mol Nutric Food Res [Internet]. 2008 Jun; 52 (Suppl 1): S103-S127. Available from: http://www.ncbi.nlm.nih.gov/pubmed/18496811

19. Ammon HPT, Wahl MA. Pharmacology of Curcuma longa. Planta Med [Internet]. 1991 Feb; 57 (1): 1-7. Available from: http://www.ncbi.nlm.nih.gov/pubmed/2062949

20. Volak LP, Ghirmai S, Cashman JR, Court MH. Curcuminoids inhibit multiple human cytochromes P450 (CYP), UDP-glucuronosyltransferase (UGT), and sulfotransferase (SULT) enzymes, while piperine is a relatively selective CYP3A4 inhibitor. Drug Metab Dispos [Internet]. 2008 Aug; 36 (8): 1594-1605. Available from: http://www.ncbi.nlm.nih.gov/pmc/articles/PMC2574 $793 /$
21. Bhattacharyya S, Ghosh S, Sil PC. Amelioration of aspirin induced oxidative impairment and apoptotic cell death by a novel antioxidant protein molecule isolated from the herb Phyllanthus niruri. PLoS One [Internet]. 2014; 9: e89026. Available from: http://journals.plos.org/plosone/article?id=10.1371/j ournal.pone.0089026

22. Das J, Ghosh J, Roy A, Sil PC. Mangiferin exerts hepatoprotective activity against D-galactosamine induced acute toxicity and oxidative/nitrosative stress via Nrf2-NFkappaB pathways. Toxicol. Appl. Pharmacol [Intenet]. 2012 Apr; 260 (1): 35-47. Available from: http://wwwsciencedirectcom.ez27.periodicos.capes.gov.br/scien ce/article/pii/S0041008X12000269

23. Ghosh S, Bhattacharyya S, Rashid K, Sil PC. Curcumin protects rat liver from streptozotocininduced diabetic pathophysiology by counteracting reactive oxygen species and inhibiting the activation of p53 and MAPKs mediated stress response pathways. Toxicol. Reports [Intenet]. 2015; 2: 365376. Available from: http://www-sciencedirectcom.ez27.periodicos.capes.gov.br/science/article/pii/ S2214750014001711

24. Ghosh S, Banerjee S, Sil PC. The beneficial role of curcumin on inflammation, diabetes and neurodegenerative disease: A recent update. Food Chem Toxycol [Internet]. 2015; 83: 111-124. Available from: http://www.ncbi.nlm.nih.gov/pubmed/2606636 